\title{
ELASTOPLASTIC CONSOLIDATION SOLUTIONS FOR SCALING FROM SHALLOW PENETROMETERS TO PIPELINES
}

Manuscript submitted to Canadian Geotechnical Journal on 14 June 2016

Revised on the $06^{\text {th }}$ December 2016

\author{
Y. Yan ${ }^{12}$, D. J. White ${ }^{1}$ and M. F. Randolph ${ }^{1}$
}

Keywords: Offshore engineering, Pipelines, Penetrometers, Plasticity, Numerical analysis

\section{Abstract}

The build-up of friction on seabed pipelines is an important design consideration, affecting their stability and the resulting in-service strain and fatigue. The consolidation beneath a partially embedded pipeline has been investigated in the past and linked to the build-up of axial pipesoil resistance. This paper extends previous work by providing solutions for consolidation around a new class of shallow penetrometer, to provide a basis to scale from site investigation results directly to the build-up of pipeline friction. Small strain finite element analyses, using Modified Cam clay soil model, are presented for the novel toroid and ball penetrometers. The effects of initial penetrometer embedment, device roughness, strength gradient and overload ratio have been explored in a comprehensive manner, and are compared with pipe results. The toroid penetrometer shows excellent agreement with an element of an infinitely long pipe, simplifying the scaling process. The ball penetrometer shows a faster consolidation response, typically by a factor of 3 , reflecting the more effective drainage mechanisms of a three dimensional device compared to a plane strain device. The dissipation responses are fitted by simple equations to aid application in design.

\footnotetext{
${ }^{1}$ Centre for Offshore Foundation Systems, The University of Western Australia, Crawley, WA 6009, Australia

${ }^{2}$ State Key Laboratory of Hydraulic Engineering Simulation and Safety, Tianjin University, 92 No.92 Weijin Road, Nankai District, Tianjin, 300072 (Corresponding author:Yue Yan)
} 


\section{INTRODUCTION}

Subsea pipelines serve as a significant component of offshore oil and gas developments, to connect wells with other facilities and for export of processed hydrocarbons, and are usually laid directly on the seabed. After the pipeline-laying process, on soft clay excess pore pressure is present in the surrounding soil. As it dissipates, a significant rise in pipe-soil resistance occurs reflecting the increase in effective stress. This has an influence on the global stability of the pipeline, including the lateral buckling and axial pipeline walking in response to thermal cycles during operation. The same mechanism affects the capacity of shallow subsea foundations, which rises after installation due to consolidation (Gourvenec et al. 2014).

Early work into the post-laying consolidation around pipelines by Gourvenec \& White (2010) and Krost et al. (2011) considered elastic, uniform soil and a smooth pipe-soil interface. Coupled consolidation finite-element analyses were later presented by Chatterjee et al (2012) using Modified Cam Clay model in ABAQUS by means of both large-deformation finiteelement (LDFE) and small-strain finite-element (SSFE) methods. The effects of embedment, rough and smooth interface conditions and large deformations associated with the penetration were investigated. These solutions have practical value in allowing prediction of the consolidation-induced changes in bearing capacity of a pipeline, and the increase in pipe-soil interface friction build-up to be predicted. These allow the pipeline design to be optimised.

However, practical application of these solutions requires an estimate of the coefficient of consolidation of the shallow near-surface soils, typically at a depth of $<0.5 \mathrm{~m}$. Conventional site investigation tools such as the cone penetrometer are not suited to these near-surface conditions, as itsthe dissipation process ensolidation-is governed by dissipation-drainage towards in-the far field, without the influence of permeable top soil surface (Chatterjee et al., 2014). Yan et al. (2010, 2011) proposed a new class of shallow ball- and toroid-shaped penetrometers specifically for investigating shallow seabed properties and determined bearing factors for undrained penetration, allowing strength profiles to be back-calculated from penetration resistance.

This paper follows from extends the previous studies into to present coupled analysis of undrained penetration then and consolidation for around a pipe, by exploring the behaviour of and the toroid and ball penetrometers, using the Modified Cam Clay model in ABAQUS. The main aim is to explore and compare-quantify the consolidation characteristics of shallowly embedded objects, in terms of the time-scale for consolidation, with the aim of allowing simple 
56 scaling from the penetrometer results to the-pipeline and foundation behaviour. The derived $\underline{\text { solutions can be used to interpret dissipation results from this new class of penetrometers, to }}$ provide estimates of the consolidation parameters. These interpretations therefore unlock a new method to accurately determine near-surface consolidation parameters to support pipeline and may also be applicable to the design of shallow foundations such as the steel mudmats used to suppert subsea infrastructuredesign.

A range of variables are allowed for, including for embedment depth (expressed as the depth of the invert of the pipe or penetrometer, $w$, normalised by the diameter $D$ ), over-load ratios (OLRs) relevant for field situations (Jewell and Ballard 2011; White et al. 2011), pipe interface roughness (extreme cases for fully smooth and rough) and consolidation coefficient profile ( $\mathrm{c}_{\mathrm{v}}$ is either uniform or increasing proportionally with depth according to the effective stress level). The OLR is the ratio between the vertical load applied to the seabed during consolidation (i.e. the submerged self-weight for the case of the pipeline), $W$, divided by the initial undrained bearing capacity (i.e. maximum penetration resistance) at that depth, $V_{\max }$.

\section{Kinematic mechanisms during undrained penetration and subsequent consolidation}

The study assumed a wished-in-place pipe, toroid or ball geometry with embedment ratio $w / D$ ranging from 0.1 to 0.5 . For each embedment depth, the pipe was displaced vertically by $0.1 D$ in an undrained manner in order to mobilise the bearing capacity at the pre-embedded depth. The specified overloading ratio, OLR $=V_{\max } / W$ (considering values of 1,4 and 12 ) was then achieved by reducing the vertical load, which established the initial excess pore pressure distribution. The subsequent consolidation response was then examined, quantifying the timerelated excess pore pressure dissipation.

During the whole consolidation responses, vertical equilibration on the pipe must be satisfied (Figure 1), so that:

$$
\int \sigma_{\mathrm{ni}}^{\prime} \cos \theta \delta A+\int \Delta u_{\mathrm{N}, \mathrm{i}} \cos \theta \delta A+\int \tau_{\mathrm{fi}} \sin \theta \delta A=W
$$

where $\theta$ is the inclination from the vertical, $\delta A$ is a local element of surface area and $\sigma_{\text {ni }}$, $\tau_{\mathrm{fi}^{\prime}}$ and $\Delta u_{\mathrm{N}, \mathrm{i}}$ are the local effective contact stress, shear stress and local effective vertical stress and excess pore pressure (hydrostatic pressure being ignored) respectively. The three components are integrated over the surface area of the embedded objects, balancing the resultant vertical loading $W$. 


\section{FINITE ELEMENT ANALYSES}

\section{Soil Model and Parameters}

The soil was modelled using Modified Cam clay (Roscoe and Burland 1968), as implemented in ABAQUS. The soil response was taken as linear elastic before yielding. All parameters used for the numerical analyses are listed in Table 1 . The selected soil parameters were chosen to be similar to those measured for kaolin clay used for centrifuge model tests by Stewart (1992) and House et al. (2001). For more detailed discussion refer to Lu (2004).

A difficulty when using the MCC model is to define a unique $c_{\mathrm{v}}$, to normalise dissipation processes and quantify the average consolidation characteristics. During the consolidation response, the soil volumetric stiffness $\left(1 / m_{\mathrm{v}}\right)$ changes with mean effective stress (and whether the soil is loading or unloading) and hence the consolidation coefficient varies with the mean effective stress and load path.

For convenience, an initial invert value of $c_{\mathrm{V}}$ is adopted for normalisation, where the $c_{\mathrm{v}}$ value is expressed using the initial soil state and (plastic) isotropic compressibility, $\mathrm{m}_{\mathrm{v}}$ as

$$
c_{\mathrm{v}}=\frac{k}{m_{\mathrm{v}} \gamma_{\mathrm{w}}}=\frac{k\left(1+e_{0}\right) p_{0}^{\prime}}{\lambda \gamma_{\mathrm{w}}}
$$

where $k$ is permeability, and $e_{0}$ (initial void ratio) and $p^{\prime}{ }_{0}$ (initial effective stress) are taken as the virgin (undisturbed) values at the depth of the object invert, prior to penetration.

In order to investigate how the timescale for consolidation varies with the distribution with depth of $c_{\mathrm{v}}$, two separate series of analyses were undertaken:

(a) homogenous case: with an artificial surcharge of $200 \mathrm{kPa}$ applied at the soil surface (including on top of the embedded part of the pipe, toroid or ball) (Figure 2), giving an approximately uniform value of $c_{\mathrm{v}}$ within the soil domain.

(b) linear case: with a very small surcharge of $0.001 \mathrm{kPa}$, giving essentially a linear increase of $c_{\mathrm{v}}$ with depth.

Comparison of these two series allowed assessment of the effective $c_{\mathrm{V}}$ for the latter case in order to obtain similar consolidation timescale as for the homogeneous case.

In all analyses the soil was initially $\mathrm{K}_{0}$-consolidated (Wroth 1984), with $\mathrm{K}_{0}$ given by

$$
K_{0 \mathrm{nc}}=1-\sin \varphi_{\mathrm{tc}}^{\prime}=0.6 \quad\left(\varphi_{\mathrm{tc}}^{\prime}=23.5^{\circ}\right)
$$


115 where $\varphi^{\prime}$ tc is the friction angle for triaxial compression conditions.

116 In situ effective stresses and pore pressures vary with depth according to the respective self-

117 weights. The initial size of yield locus is determined by $\mathrm{p}_{\mathrm{c}}$, expressed as

118

$$
p_{\mathrm{c}}^{\prime}=\frac{q_{0}^{2}}{M^{2} p_{0}^{\prime}}+p_{0}^{\prime}
$$

119

121

$$
\sin \varphi_{\mathrm{te}}^{\prime}=\frac{3 M}{6-M}
$$

When plane strain conditions prevail, with $\sigma_{2}^{\prime}=0.5\left(\sigma_{1}^{\prime}+\sigma_{3}^{\prime}\right)$, the critical state corresponds to

where $p_{0}^{\prime}$, and $q_{0}$ are the initial effective mean stress and deviatoric stress, respectively, at a given depth. The initial void ratio $\mathrm{e}_{0}$, can be calculated from

$$
e_{0}=e_{\mathrm{N}}-\kappa \ln p_{0}^{\prime}-(\lambda-\kappa) \ln p_{\mathrm{c}}^{\prime}
$$

$$
e_{\mathrm{N}}=e_{\mathrm{cs}}+(\lambda-\kappa) \ln (2)
$$

where $\kappa$ and $\lambda$ are the usual swelling and compression indices in MCC.

For these initial conditions, the starting point of the analyses for a given depth is denoted by 'O' in $p^{\prime}-q$ and $e-\ln p$ ' spaces, as shown in Figure 3 (a). The stress path to reach critical state for an element that is sheared during undrained penetration is denoted by OB.

Figure 3 (b) shows the regular Tresca hexagon plotted in the deviatoric plane and von Mises circle (MCC failure criterion on the deviatoric plane). The comparison of the modelling using two yield criteria (Tresca and MCC) provides an indication of the mode of deformation during failure.

When triaxial conditions dominate the failure mechanism (Lode angle $\theta= \pm 30^{\circ}$ ), $S_{\text {utc_MCC }}=s_{\mathrm{u}_{\_} \text {Tresca. }}$. When plane strain conditions dominate the failure mechanism (Lode angle $\left.\theta=0^{\circ}\right), s_{\text {ups }}=1.15 s_{\text {u,Tresca }}=1.15 s_{\text {utc_MCC. }}$.

The critical state corresponds to the following internal friction angles:

$$
\sin \varphi_{\mathrm{tc}}^{\prime}=\frac{3 M}{6+M}
$$

$$
\text { an internal friction angle of: }
$$




$$
\sin \varphi_{\mathrm{ps}}^{\prime}=\frac{\sigma_{1}^{\prime}-\sigma_{3}^{\prime}}{\sigma_{1}^{\prime}+\sigma_{3}^{\prime}}=\frac{q}{\sqrt{3} p^{\prime}}=\frac{M}{\sqrt{3}}
$$

140 where $M$ is the slope of the critical state line, and $\varphi_{\text {tc }}^{\prime}, \varphi_{\text {te }}^{\prime}, \varphi_{\mathrm{ps}}^{\prime}$, are the friction angles under

141 triaxial compression, triaxial extension and plane strain conditions.

142 For soil with $M=0.92$, as assumed in this study, these equations lead to interface friction

143 coefficients for a rough interface of 0.53 , which corresponds to shearing in plane strain 144 conditions.

145 For triaxial compression conditions, the undrained shear strength ratio $s_{\mathrm{u}} / \sigma_{\mathrm{v}}^{\prime}$ for $K_{0}$

146 consolidated soil can be calculated from the MCC parameters using (Wroth 1984)

$$
\frac{s_{\mathrm{ut}}}{\sigma_{v}^{\prime}}=\frac{\sin \varphi_{\mathrm{tc}}^{\prime}}{2 a}\left(\frac{a^{2}+1}{2}\right)^{\Lambda}
$$

148 For plane strain conditions the undrained shear strength ratio can be expressed as

$$
\frac{s_{\mathrm{ups}}}{\sigma_{\mathrm{v}}^{\prime}}=\frac{2}{\sqrt{3}} \frac{\sin \varphi_{\mathrm{tc}}^{\prime}}{2 a}\left(\frac{a^{2}+1}{2}\right)^{\Lambda}
$$

151 Where

$$
a=\frac{3-\sin \varphi_{\mathrm{tc}}^{\prime}}{2\left(3-2 \sin \varphi_{\mathrm{tc}}^{\prime}\right)}
$$

$$
\Lambda=\frac{\lambda-\kappa}{\lambda}
$$

154 This leads to $\left(\mathrm{s}_{\mathrm{ups}} / \sigma^{\prime}{ }_{\mathrm{v} 0}\right)_{\mathrm{nc}}$ of 0.29 and mudline (plane strain) strengths of 0 (actually $0.00029) \mathrm{kPa}$ and $57 \mathrm{kPa}$ for the 0.001 and $200 \mathrm{kPa}$ surcharge cases, respectively.

\section{Pipe, toroid and ball penetrometer properties}

157 The pipe, toroid and ball were modelled as rigid bodies with unit weight equal to the saturated 158 unit weight of the soil, which facilitated reaching equilibrium under the geostatic stresses. The

159 penetration resistance $V$ in the subsequent step, which was applied as an external force to the 160 rigid body, therefore did not include any component of soil buoyancy. The interface conditions 161 considered were fully rough (soil bonded to pipe, toroid and ball) and fully smooth (zero shear stress at pipe, toroid and ball surface), with pore water flow normal to the pipe surface always 
163

164

165

166

167

168

169

170

171

172

173

174

175

176

177

178

179

180

181

182

183

184

185

186

187

188

set to zero.

The ratio between the outer and inner diameters of the toroid was 2. This ratio was identified by Yan et al. (2011) as sufficient to practically eliminate interference between opposite sides during undrained penetration.

\section{Finite element mesh}

Although a plane strain model would have been sufficient for the pipe model, the analyses were undertaken using a slice (normal to the pipeline axis) of three-dimensional eight-noded hexahedral elements, with multiple constraints forcing an identical response of the corresponding nodes on each lateral face of the slice, thus imposing longitudinally-uniform conditions (Figure 4). The reason for using a three-dimensional model was that this model was also used to explore axial motion of the pipe segment (Yan et al. 2014). One slice of the soil domain for the pipe included 3602 elements.

Similarly, for the toroid and ball, the analysis was undertaken using a ten-degree-wedge of eight-noded hexahedral elements, with multiple constraints forcing identical response of the corresponding nodes on each circumferential face of the slice, thus imposing axisymmetric and circumferentially-uniform conditions.

For all models, the soil domain extended $8 D$ horizontally and $10 D$ vertically from the centreline of the embedded objects, with zero horizontal displacements on the lateral boundaries, zero vertical displacement at the base and drainage allowed only at the upper surface. The ten-degree soil models for the toroid and ball penetrometers comprised 2998 and 3310 elements respectively. This method allowed the three dimensional problems to be modelled at considerably reduced computational expense, by analysing only a small radial slice of the model.

\section{Model and mesh validation}

The numerical FE model was validated in a step-by-step fashion to confirm the correct use of the MCC soil model (for both surcharges of $200 \mathrm{kPa}$ and $0.001 \mathrm{kPa}$ ). The mesh sensitivity using the Tresca model is first validated against the published results, which shows sufficient robustness (more details are provided in the next section). The same meshing strategy was therefore adopted for the MCC soil model.

Figure 5 presents the undrained vertical capacity factors $\left(V / A s_{\mathrm{u}, \text { invert }}\right.$, with $A$ the projected area in plan view, and $s_{u, i n v e r t}$ the plane strain invert shear strength calculated from the in situ profile 
194 based on equations (8) and (9) for a deeply embedded object ( $w / D=0.5$ for pipe, toroid, and ball) from the MCC models. These results are compared with the FE modelling for the (inscribed) Tresca soil.

For all pipe and ball cases with the $0.001 \mathrm{kPa}$ surcharge, the MCC model generally gives consistent agreement with the Tresca model (though 4 to 7\% higher). This suggests that the soil in the plastic zone is mostly sheared under plane strain conditions.

All responses using the $200 \mathrm{kPa}$ surcharge show a softer build-up of resistance, and do not quite reach a plateau within the applied displacement of $0.1 D$ for the rough cases. This is due to differences in rigidity index $\left(G / s_{\mathrm{u} 0}\right)$ for the MCC and Tresca model, which were 150 and 333 respectively. A set of analyses $(w / D=0.5)$ undertaken using an identical $G / s_{\mathrm{u}}$ for the MCC and Tresca model, gave a discrepancy of less than $4 \%$ at the plateau (reached within a displacement of $0.1 D$ ) for the pipe, and $7 \%$ for the ball. This also suggests that most soil in the plastic zone is sheared under plane strain conditions for the different objects.

\section{UNDRAINED PENETRATION RESPONSE}

The limiting undrained penetration resistances, for embedment ratios of 0.1 to 0.5 , are compared with published values for pipe, toroid and ball in Table 2 (Randolph et al. 2000; Randolph and White 2008; Merifield et al., 2009; Yan et al. 2011). The penetration resistances using the MCC soil model have been normalised by the relevant projected contact area in plan view and the plane strain shear strength at invert level. The results using a simple Tresca soil model are also tabulated and show close agreement. Comparative results of the WIP (wishedin-place) and PIP (pushed-in-place) analyses using a simple Tresca soil model are also shown. The PIP results are up to $7 \%$ higher than the corresponding WIP results at shallower embedment, and generally give close agreement at deep embedment.

The FE results for the nominal surcharge of $200 \mathrm{kPa}$ for the three objects generally show excellent agreement with rigid plastic limit analyses. For the nominal surcharge of $0.001 \mathrm{kPa}$, the normalised resistances calculated from MCC are consistently higher than those calculated from the Tresca soil model, around 6-8\% for toroid and pipe, and around 3\% for ball. This might beis consistent with observations of centrifuge modelling on a toroid penetrometer (Yan et al., 2011), that the Tresca model gives a enseslight under-prediction (comparing the smooth case with the centrifuge results).

These results provide further confirmation that the MCC model is performing correctly in undrained conditions. The following consolidation analyses were undertaken following 
undrained penetration displacement by $0.1 D$.

\section{CONSOLIDATION RESPONSE}

\section{Pore pressure dissipation at object invert}

229 After penetration, the specified vertical load was applied, factoring the maximum penetration

230 load to reflect overloading, and then maintained constant while consolidation was permitted.

231 Contours of initial excess pore pressure normalised by the invert value for the pipe and ball 232 geometry are shown for $w / D=0.5$ in Figure 6 and corresponding variations around the 233 periphery are shown in Figure 7. For the $0.001 \mathrm{kPa}$ surcharge case, the excess pore pressure is more concentrated towards the object invert, reflecting the increasing soil strength with depth, and therefore the concentration of load at the object invert. In uniform soil conditions, the excess pore pressure is almost uniform $( \pm 15 \%)$ over most of the surface of the embedded objects $(0.4<x / D<0.4)$. Figure 6 shows that the excess pore pressure field for the toroid follows very closely that for the pipe, indicating that the adopted ratio of the internal and external toroid diameters is adequate to eliminate interference between opposite sides. The ball penetrometer has a more compact excess pore pressure field due to the three dimensional geometry. This gives a shorter drainage path for a given embedment.

242 Figure 8 shows variations of excess pore water pressure at the invert of the objects, normalised

243 by the initial value, with non-dimensional time $T$. The invert pore pressure is relevant to the 244 interpretation of penetrometer tests, because the ball and toroid penetrometers are equipped 245 with pore pressure transducers at this position.

246 The majority of the results are well fitted by simple hyperbolic equations (shown as solid lines) 247 in the form of

$$
\frac{\Delta u}{\Delta u_{\mathrm{i}}}=\frac{1}{1+\left(T / T_{50}\right)^{m}}
$$

249 where $T_{50}$ is the value of $T$ for $50 \%$ dissipation and $\mathrm{m}$ is a constant.

250 It can be seen that, for a rough embedded object, there is an initial increase in invert excess pore 251 pressure for all embedment ratios. This is due to the Mandel-Cryer effect (Cryer 1963; Mandel 1963) as discussed for consolidation beneath a pipe by Gourvenec and White (2010) and a skirted foundation by Gourvenec and Randolph (2010). The effect is essentially determined by comparison of the early rate of development of effective stress and excess pore pressures at the 
invert and the soil at the edges of the object. For the rough interface, the excess pore pressure is distributed more evenly on the interface, and the soil near to the edge (and hence the free surface) consolidates more quickly than the invert soil, which leads to the Mandel-Cryer effect at the invert. The effect is evident for each embedment, and for all rough objects. Due to the Mandel-Cryer effect, the hyperbolic fit does not capture the initial portion of the dissipation responses for rough objects. The smooth pipe (and other objects) are unaffected by the MandelCryer effect, as the excess pore pressure is more concentrated at the invert.

Table 3 summarises the fitting values of $T_{50}$ and $\mathrm{m}$ for different embedment levels for all three objects. The dissipation for the toroid follows closely the behaviour for the pipe. The normalised time factors for dissipation for the ball range between 2 and 4 times lower than for the pipe or toroid, with an average ratio of about three for a given degree of dissipation. The implied higher rate of excess pore pressure dissipation around the ball is consistent with the smaller volume of soil involved during penetration, and more effective drainage due to the three dimensional geometry.

For the extreme embedment ratios $(w / D=0.1$ and 0.5$)$, results are also shown in Figure 8 for $0.001 \mathrm{kPa}$ surcharge (with a high depth gradient of $c_{\mathrm{V}}$ ). For those cases, the $c_{\mathrm{v}}$ values that give a good match to the uniform cases at $\mathrm{T}_{50}$ and during the latter part of the consolidation curve

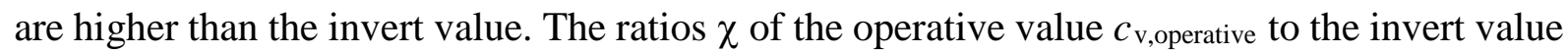
are summarised in Table 4. The ratios lie in the range $2.5-4.0$, indicating more rapid dissipation than if the entire soil domain had the same $c_{\mathrm{v}}$ value as at the invert. This is linked to the higher $c_{\mathrm{V}}$ within the consolidating soil beneath the pipe invert and the different initial pore pressure field. An alternative interpretation of this effect is to consider the depths at which the operative $c_{\mathrm{V}}$ is found, which are also shown in Table 4.

\section{Average pore pressure dissipation around object surface}

The decay in the average excess pore pressure around the pipe periphery $U_{\text {av }}$ and the corresponding rise in normalised average normal effective stress $\Sigma$ are useful quantities. They are related to the volumetric change of the soil adjacent to the objects, which indicates the increase in shear strength due to reconsolidation after installation. This potentially-reflects the build-up of axial or sliding resistance between the embedded objects and the seabed (Yan, 2013). The factors $U_{a v}$ and $\Sigma$ can be defined as The decay in the average excess pore pressure around the pipe periphery $U_{a v}$ and the corresponding rise in normalised average normat effective stress $\Sigma$ are useful quantities since they indicate the build-up of potential axial 


$$
U_{\text {av }}=\frac{U}{U_{\mathrm{i}}}=\frac{\int \Delta u \delta A}{\int \Delta u_{\mathrm{i}} \delta A}
$$

$$
\Sigma=\frac{\int \sigma_{\mathrm{n}}^{\prime} \delta A-\int \sigma_{\mathrm{n}, \mathrm{init}}^{\prime} \delta A}{\int \sigma_{\mathrm{n}, \mathrm{f}}^{\prime} \delta A-\int \sigma_{\mathrm{n}, \text { nit }}^{\prime} \delta A}
$$

where $U$ is the integrated excess pore pressure $\Delta u$ around periphery, $\sigma^{\prime}{ }_{n}$ denotes the normal effective stress, and $\sigma_{n, a v, \text { init }}^{\prime}$ and $\sigma_{n, a v, f}^{\prime}$ are the values before and after dissipation.

These trends are shown in Figure 9 for the embedded objects. The averaged pore pressure and inverted effective stress responses agree to within 5\% throughout the decay process, indicating that the changes in total normal stress on the object surface are small. The pipe results calculated from the MCC model are similar to the elastic results, but show more rapid dissipation as consolidation progresses compared with the elastic solution, reflecting increasing stiffness as the effective stress rises.

The majority of the pore pressure dissipation results shown in Figure 9 are well fitted by simple exponent equations in the form of

$$
U_{\mathrm{av}}=1-\Sigma=0.5^{\left(\frac{T}{T_{50}}\right)^{n}}
$$

where $U_{\text {av }}$ and $\Sigma$ are the average excess pore pressure, and average normal effective stresses around the pipe periphery. $T_{50}$ is the value of $T$ for $50 \%$ dissipation, $\mathrm{n}$ is a constant (summarised in Table 5).

The rough objects exhibit more consistent consolidation responses during the initial dissipation, up to $20 \%$ dissipation around the pipe or toroid periphery and up to $30 \%$ dissipation at the ball periphery. This consistent trend of decay of pore pressure is due to the evenly distributed excess pore pressure at the rough interface. As consolidation progresses, the time for dissipation is prolonged for increasing embedment, reflecting the variation in the drainage distance with increasing embedment. The fitted curves show decreasing fitting parameter $\mathrm{n}$ with increasing embedment ratio, reflecting this feature.

Figure 10 summarises values of $T_{50}$ observed (a) for the invert pore pressure dissipation, and 
314 (b) for the averaged perimeter dissipation, with increasing $w / D$ for the three objects. This provides a simple comparison of the relative rates of consolidation. The $T_{50}$ values for the penetrometer invert can be compared to those for a piezocone (Teh and Houlsby 1991), of around 0.5 to 1 , depending on the soil rigidity index. The surface penetrometers therefore exhibit much shorter consolidation times than for a deeply embedded cone.

It can also be observed that the excess pore pressure at the invert of rough objects generally dissipates more slowly than for smooth objects, due to the Mandel-Cryer effect. By contrast, 321 for the averaged excess pore pressure around the periphery, rough objects show faster 322 dissipation, reflecting the effect of the initial excess pore pressure field distribution.

323 It is notable that tThe parameters summarised in Table 3 and Table 5 provides a method to transfer the invert response to the average response around the perimeter of the objects perimeter response, allowing for-assessment of build up ofof the increase in potential axial resistance between the objects and soil. The more preferable method may be amounting more pore pressure transducers along the device periphery for a more direct measurement of the average response.

\section{Effect of overloading ratio and object roughness}

330 Excess pore pressure dissipation responses for the toroid and ball penetrometers, with 331 overloading ratios of 1, 4, and 12, are illustrated in Figure 11 for the extreme embedment ratios of 0.1 and 0.5 . The dissipation responses for high overloading show dilatory behaviour, with pore pressure increasing from the initial value to a maximum followed by a decrease to the hydrostatic value.

The initial excess pore pressure field generated during undrained penetration has a comparable extent and magnitude for a given object with a given embedment and interface condition, irrespective of the overloading ratio applied. The rough objects result in a pore pressure field more evenly distributed on the periphery, while the smooth objects result in a pore pressure

339 field more concentrated at the invert.

340 The overloading event led to the generation of negative excess pore pressure around the embedded objects, but positive excess pore pressure remains in the far field. For most cases

342 with OLR $>1$, an increase of excess pore pressure (swelling) was observed during the initial 343 period of time, as flow from the far field towards the periphery exceeds the rate of dissipation 344 from the periphery to the free drainage surface. The dissipation time decreases for increasing 345 overloading ratio reflecting this neutralisation of excess pore pressure. Although dissipation is 
346 initially faster for the rough objects than the smooth, the time histories of consolidation soon

347 become closely banded and the consolidation responses for rough and smooth objects 348 eventually converge to similar time factors for full consolidation.

349 Additional illustration of these phenomena is provided by the stress paths depicted in $e-\ln \left(p^{\prime}\right)$ 350 space as shown in Figure 12 (for overloading ratios of 1, 4, and 12 under surcharge of $200 \mathrm{kPa}$ ). 351 To aid interpretation of the stress paths, the states are denoted with superscript 1 , 2, and 3 for 352 overloading ratios of 1,4 , and 12 respectively. The initial state is denoted by $O$ at the in situ 353 effective stress $\left(p^{\prime}=\sigma^{\prime}{ }_{\mathrm{v} 0}\left(1+2 K_{0}\right) / 3\right)$, from which state the soil is loaded along an undrained stress path during penetration from $\mathrm{O}$ to $\mathrm{B}_{1}$. In the unloading step to establish the overload ratio, the excess pore pressure at the interface falls significantly to balance the residual applied force, while the effective stress remains virtually constant (remaining at B') in e-ln(p') space. The soil in the far field is largely unaffected by this unloading event, and the effective stress and the excess pore pressures remain at a similar magnitude as for the OLR $=1$ case. This forms a drainage front advancing towards the surface of the object and the soil mass. This in turn increases the excess pore pressure at the object ( $B_{1}$ to $B_{2}$ for case of OLR $=4$, and $B_{2}$ to $B_{3}$ for case of OLR =12). With time, the process begins to reverse and the dissipation at the invert begins ( $B_{2}$ to $C_{2}$ for case of $O L R=4 ; B_{3}$ to $C_{3}$ for case of OLR $=12$ ).

COMPARISON WITH FIELD AND NUMERICAL DATA AND AVAHLABLE PUBLISHED-RESULTS

The dissipation curves from numerical analyses in this study and large-deformation finite element (LDFE) analyses (Chatterjee et al., 2012) for a half embedded ( $w / D=0.5)$, smooth pipe in homogeneous case isare illustrated in Fig. 13. Only minimumal discrepancy ofbetween them is foundevident, which provides the-validitiony of the numerical solution in this study. The field data (the average excess pore pressure from four invert-mounted transducersrecording plotted against elapsed time) is extrapolated from a published field test (Hill and Jacob, 2008). This test was implemented offshore via the Fugro SMARTPIPE device. During

372 the test, sucha model pipe with a length of $1.1 \mathrm{~m}$ and a diameter of $0.225 \mathrm{~m}$ wais first penetrated 373 to a depth of $0.6 \mathrm{D}$ in a soft clay seabed. It was then held under a constant vertical load with the 374 decay of excess pore pressure being recorded by four transducers spaced along the pipe invert. 375 To obtain good agreement between the field data and the numerical result, an operative $C_{\text {vaperative }}$ 376 of $48 \mathrm{~m}^{2} /$ year is adopted to normalise the field data based on the uniform soil case. The invert $377 \underline{\epsilon}_{v, \text { invert }}-$ of this model pipe can also be estimated from suggested scaling factor $\chi$ presented in 
378 Table 4 . The value of $\chi$ is ranged within 12.5 for the case of $w / D=0.5$, herein the value of $\chi$ 379 is chosen as 2.5, which yieldsUsing the linear soil case, an invert value of the $C_{\text {vinvert }}$ ef $=$ $380 \quad 20 \mathrm{~m}^{2} /$ year applies. It can be seen the dissipation response of field data normalised by such $381 \underline{\epsilon}_{v, \text { invert follows close agreement with numerical result of normally consolidated caseThis is a }}$ 382 relatively narrow range of uncertainty, which could be reduced if the penetration resistance data 383 was available, allowing the appropriate soil profile to be selected. Using this back calculated $384 \underline{c}_{\mathrm{v}, \text { invert }}$, the consolidation degree is around $50 \%$ after $2700 \mathrm{~s}$, which corresponds tobased on $\mathrm{a}$ $385 \underline{T_{50}}$ of $=0.022 ;$ and $99 \%$ after $122035 \mathrm{~s}$, which corresponds to completion of primary 386 eonsolidation.

387 The comparison is also extended to the available published solutions of measuring for consolidation coefficient bybased on different types of devices. Apart from-In addition to the results of toroid and ball penetrometers from thise present study, the dissipation curves obtained by the strain path method for the conventional cone penetration test (CPT) (Teh and Houlsby, 1991), and simulated by the coupled large-deformation finite element (LDFE) analyses for the parkable piezoprobe test (PPP) (Chatterjee et al., 2014) in homogeneous clay are presented Fig. 14. The aforementioned dissipation responses offor a pipe are also included as a reference for comparison. The decay process of the toroid penetrometer presented in this paperhere shows a good agreement with the pipe results-of pipe, due to their similar geometry. For the same diameter, itthe toroid and pipe shows, buta faster response than the result of-CPT, and most importantly a different shape of response. It This shows that the presence of the permeable top surface alters the shape of the dissipation response as well as the overall rate, emphasising the importance of using device-specific dissipation solutions to interpret the different types of testimplies the CPT data from deep penetrated position cannot reflect the speed-up drainage fate due to the permeable top surface of soil.

402 The ball penetrometer performsshows a similar dissipation response as-to the PPP. Both show 403 a faster decay compared to toroid and pipe for the same $\mathrm{D}$, which indicates a more rapid

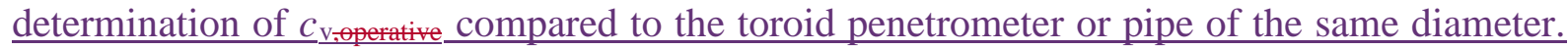
The value of $\epsilon_{v}$,invert-can also be predicted following a similar process of field data described above.

These two values can be directly used for pipe design, as the scaling factor $x$ of ball penetrometer is almost same compared to the pipe for each case (Table 4). Note that when tThese resullts show measurement using that the hemiball penetrometer provides a rapid method of is used to-estimatinge the dissipation response $\theta$ faround a pipe, given the differences 
411 in the values of $T_{50}$ (and $m$ ) need to be changed from that of ball penetrometer to pipe using suggestion of (Table 3). For instance, the dimensionless time scaling factors $-T_{50}=0.033$ for and $m=1.3$ of the smooth ball penetrometer $(w / D=0.5)$ are required to be changed tois almost three times quickshorter than $T_{50}=0.082$ and $m=1.05$ of the smooth pipe $(w / D=0.5)$.

Throughout the comparison, the numerical solutions of pipe, toroid and ball penetrometers infor the case of homogeneous easesoil, as presented here, in this paper can be used to determine

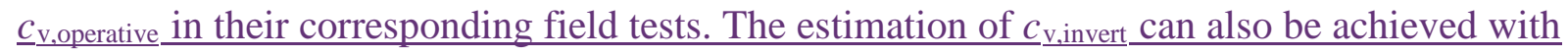
the aid of suggested scaling factors $\chi$, which isspan a relatively narrowed inte a small range by the numerical solutions of them infor the normally consolidated case. The efficiency in estimating consolidation coefficient via ball penetrometer might be highlighted since the cost of conducting such a field test isdepends mainly dependent on the vessel time.

\section{LIMITATIONS}

Although the numerical solutions reported in this paper have been capable of determination of the consolidation degree through a back-calculation of $C_{\underline{v}}$, the effect of higher hydraulic conductivity around the interface arising from the roughness and asperities of the pipe coating should be considered aroundmay have an influence at the pipe-soil interface (Jewell and Ballard, 2011). A special drainage or consolidation condition along the interface could be introduced to avoid the unexpectedly the cause of a higher coefficient of consolidation being

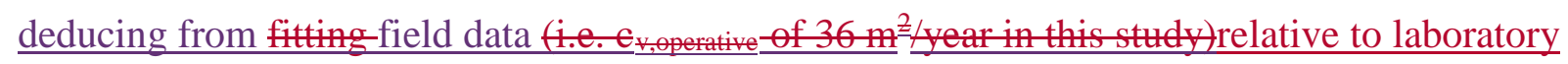
tests, using devices such as the Rowe cell. However, such an effect may also exist at the surface of a pipe, in which case the observed dissipation rate on the penetrometer is realistic for design.

AlseFinally, the process of pipe installation ishas been regarded as a-monotonic penetration followed by a consolidation, without the consideration of cyclic behaviour. A more sophisticated hyperplasticity with a non-linear kinematic hardening based on the modified Cam clay soil model (Likitlersuang and Houlsby, 2006; Apriadiet al., 2009) may be adopted to avoid non-conservative elastic response (Houlsby et al., 2005) It is possible that the consolidation rate around a pipeline may be altered by a dynamic component of the installation process which remoulds the surrounding soil and alters the initial pore pressure field. However, centrifuge model testing shows that this effect is minimal (Cocjin et al. 2017).

\section{CONCLUSIONS}

This paper presented numerical results based on the Modified Cam clay model to investigate 
442 the consolidation process after partial embedment of a pipeline and of shallow toroid and ball

443 penetrometers. This is an important consideration for design as pore pressure dissipation 444 governs the rate at which pipeline axial friction develops. These novel shallow penetrometers 445 offer an efficient basis to determine the relevant consolidation rates directly in situ. The effects on consolidation rate of embedment, object-soil interface conditions and different overloading ratios have been investigated.

448 For both smooth and rough pipes, toroids and balls, consolidation time increased with 449 increasing initial embedment, and was greater for the rough interface condition. An initial 450 increase in excess pore pressure was observed at the invert for rough embedded objects due to the Mandel-Cryer effect. Simple hyperbolic or exponential equations were fitted to the dissipation curves both at the object invert and averaged over the surface.

453 These results now provide an interpretation method for shallow ball and toroid penetrometers to determine the consolidation properties of soft soils, giving these new tools practical value. Also, the resulting values of $c_{\mathrm{v}}$ can be converted into average rates of pore pressure dissipation, to assess the rate of effective stress recovery - for example to predict the build-up of friction on seabed pipelines.

458 The consolidation responses for a toroid penetrometer generally show excellent agreement with those for an infinitely long pipe, confirming that the adopted toroid shape - specifically the ratio of internal and external diameters - is devoid of interaction effects. The shallow ball penetrometer shows a faster consolidation response, typically by a factor of 3, reflecting the more effective drainage mechanisms of a three dimensional device compared to a plane strain device. The toroid dissipation response is therefore more directly applicable in pipeline analysis, once the relative diameter of the two objects is accounted for. On the other hand, the ball provides a more rapid determination of $c_{\mathrm{v}}$, which offers improved time efficiency if required during the survey operations.

The dissipation responses were also compared with those from elastic solutions, highlighting the effects of different initial excess pore pressure distribution and some stiffness increase during consolidation arising from the MCC model.

470 It is anticipated that these solutions will allow the hemiball and toroid penetrometer to gain 471 practical acceptance as improved tools for characterising the near-surface properties of soft 472 soils. 


\section{REFERENCES}

Apriadi, D., Likitlersuang, S., Pipatpongsa, T. and Ohta, H. 2009. On the numericat implementation of hyperplasticity non-linear kinematic hardening modified cam clay model. The IES Journal Part A: Civil \& Structural Engineering, 2(3): 187-201.

Chatterjee, S., Yan, Y., Randolph M.F. and White D.J. 2012. Elastoplastic consolidation beneath shallowly embedded offshore pipelines. Géotechnique Letters, 2:73-79.

Chatterjee, S., Randolph, M.F. and White, D.J. 2014. A parkable piezoprobe for measuring cv at shallow depths for offshore design. Géotechnique 64(1), 83-88.

Cocjin M., White D.J. \& Gourvenec S.M. 2017. Softening and consolidation around seabed pipelines: centrifuge modelling. Submitted for publication, in review.

Cryer, C.W. 1963. A comparison of the three dimensional consolidation theories of Biot and Terzaghi. Q. J. Mech. Appl. Math, 16(4):401-412.

Gourvenec, S., and Randolph, M.F. 2010. Consolidation beneath circular skirted foundations. Int. J. of Geomech., ASCE 10(1):22-29.

Gourvenec, S., and White D.J. 2010. Elastic solutions for consolidation around seabed pipelines. Proc. Offshore Technology Conference, Houston, Paper OTC 20554.

Gourvenec, S. M., Vulpe, C. and Murthy, T. G. 2014. A method for predicting the consolidated undrained bearing capacity of shallow foundations. Géotechnique, 64, No. 3, 215-225.

Hill, A.J. and Jacob, H. 2008. In-situ measurement of pipe-soil interaction in deep water. Proceedings of offshore technology conference, Houston, Texas, USA, Paper OTC 19528.

Houlsby, G.T., Amorosi, A., and Rojas, E. 2005. Elastic modulli of soils dependent on pressure: a hyperelastic formulation. Géotechnique, 55(5):383-392.

Jewell, R.J., and Ballard, J.-C. 2011. Axial pipe-soil interaction - a suggested framework. Proc. Offshore Technology Conference, Houston, Paper OTC 22010.

Krost, K., Gourvenec, S., and White D.J. 2011. Consolidation around partially embedded seabed pipelines. Géotechnique, 61(2):167-173.

Likitlersuang, S. and Houlsby, G.T. 2006. Development of hyperplasticity model for soil mechanics. International Journal for Numerical and Analytical Method in Geomechanics, 30(3), 229-254. 
Lu, Q. 2004. A numerical study of penetration resistance in clay. PhD thesis, The university of Western Australia.

Mandel, J. 1963. Interference plastique de foundations superficielles. Proc. Int. Conf. on Soil Mech., Budapest.

Merifield, R.S., White, D.J., Randolph, M.F. 2009. Effect of surface heave on response of partially embedded pipelines on clay. Int. J. of Geotechnical and Geoenvironmental Engineering, ASCE 135(6):819-829.

Randolph, M.F., Martin, C.M., and Hu, Y. 2000. Limiting resistance of a spherical penetrometer in cohesive material. Géotechnique, 50(5):573-582.

Randolph, M.F., and White, D.J. 2008. Upper-bound yield envelopes for pipeline at shallow embedment in clay. Géotechnique, 58(4):297-301.

Roscoe, K.H., and Burland, J.B. 1968. On the generalised stress-strain behaviour of 'wet cyaly'. Engineering plasticity, Cambridge University Press.

Stewart, D.P. 1992. Lateral loading of piled bridge abutments due to embankment construction. $\mathrm{PhD}$ thesis, The university of Western Australia.

Teh, C.I., and Houlsby, G.T. 1991. An analytical study of cone penetration test in clay. Géotechnique, 41(1):17-34.

White, D.J., Ganesan, S.A., Bolton, M.D., Bruton, D.A.S., Ballard, J.-C., and Langford, T.E. 2011. SAFEBUCK JIP - Observation of axial pipe-soil interaction from testing on soft natural clays. Proc. Offshore Technology Conference, Houston, Paper OTC 21249.

Wroth, C.P. 1984. The interpretation of in situ soil tests. Géotechnique, 34(4):449-489.

Yan. Y., White, D.J. and Randolph, M.F. 2010. Investigation into novel shallow penetrometers for fine-grained soils. Proc. $2^{\text {nd }}$ Int. Symp. on Frontiers in Offshore Geotechnics, 321326.

Yan. Y., White, D.J. and Randolph, M.F. 2011. Penetration resistance and stiffness factors for hemispherical and toroidal penetrometers in uniform clay. Int. J. of Geomech., ASCE 11(4):263-275.

Yan. Y., White, D.J. and Randolph, M.F. 2014. Cyclic consolidation and axial friction for seabed pipelines. Géotechnique Letters, 4:165-169. 


\section{TABLES}

538 Table 1 Input parameters of numerical study

539 Table 2 Summary of (fully mobilised) undrained bearing capacities for pipe, toroid and

540 ball

541 Table 3 Values of $\boldsymbol{T}_{\mathbf{5 0}}$ and constant $\boldsymbol{m}$ of hyperbolic fits to invert pore pressure dissipation

542

543 Table 4 Operative $c_{v}$ for different initial embedment values

544 Table 5 Values of $\boldsymbol{T}_{50}$ and constant $\boldsymbol{n}$ of exponents fits to periphery pore pressure 
Table 1 Input parameters of numerical study

\begin{tabular}{l|l}
\hline Soil property Parameters & Values \\
\hline $\begin{array}{l}\text { Slope of critical state line }(\mathrm{CSL}) \text { in } p^{\prime} \text { - } q \text { space, } M \text { (friction angle in triaxial } \\
\text { compression, } \varphi^{\prime} \text { tc) }\end{array}$ & $0.92\left(23.5^{\circ}\right)$ \\
Void ratio at $p^{\prime}=1 \mathrm{kPa}$ on $(\mathrm{CSL}), e_{\mathrm{cs}}$ & 2.14 \\
Slope of the virgin compression line in $e$-ln $\left(p^{\prime}\right)$ space, $\lambda$ & 0.205 \\
Slope of the swelling and recompression line in $e$-ln $\left(p^{\prime}\right)$ space, $\kappa$ & 0.044 \\
Elastic shear modulus, $G$ & $50 \mathrm{p}_{0}{ }^{\prime}$ \\
Saturated bulk unit weight, $\gamma_{\mathrm{sat}}: \mathrm{kN} / \mathrm{m}^{3}$ & 15.0 \\
Unit weight of water, $\gamma_{\mathrm{w}}: \mathrm{kN} / \mathrm{m}^{3}$ & 10 \\
Permeability of soil, $k$ : $\mathrm{m} / \mathrm{s}$ & $1.0 \times 10^{-9}$ \\
\hline Pipe/Toroid/Ball diameter, $D: \mathrm{m}$ & 0.5 \\
(although all results are presented in non-dimensional form) & \\
\hline
\end{tabular}


Table 2 Summary of (fully mobilised) undrained bearing capacities for pipe, toroid and ball

\begin{tabular}{|c|c|c|c|c|c|c|c|c|c|c|c|c|c|c|c|c|}
\hline \multirow{5}{*}{ Objects } & \multirow{5}{*}{$w / D$} & \multicolumn{8}{|c|}{ This study } & \multirow{2}{*}{\multicolumn{7}{|c|}{$\begin{array}{c}\text { References } \\
\text { Tresca }\end{array}$}} \\
\hline & & \multirow{2}{*}{\multicolumn{4}{|c|}{$\begin{array}{c}\text { Tresca } \\
\text { FE }\end{array}$}} & \multirow{2}{*}{\multicolumn{4}{|c|}{$\frac{\text { MCC }}{\text { FE }}$}} & & & & & & & \\
\hline & & & & & & & & & & & Upper & ound ${ }^{\mathrm{c}, \mathrm{d}}$ & & $\mathrm{FE}^{\mathrm{e}}$ & & $E^{f}$ \\
\hline & & \multicolumn{2}{|c|}{ Homo } & \multicolumn{2}{|c|}{ Non-homo } & \multicolumn{2}{|c|}{ Homo $^{\mathrm{a}}$} & \multicolumn{2}{|c|}{ Non-homo ${ }^{\mathrm{b}}$} & \multicolumn{2}{|c|}{ Homo } & \multicolumn{2}{|c|}{ Non-Homo } & Homo & \multicolumn{2}{|c|}{ Homo } \\
\hline & & Rough & Smooth & Rough & Smooth & Rough & Smooth & Rough & Smooth & Rough & Smooth & Rough & Smooth & Rough & Rough & Smooth \\
\hline \multirow{5}{*}{ Pipe } & 0.10 & 3.17 & 2.77 & 3.78 & 3.00 & 3.24 & 2.84 & 4.02 & 3.24 & 3.35 & 2.79 & 3.88 & 3.02 & 3.27 & 3.32 & 2.98 \\
\hline & 0.20 & 4.18 & 3.48 & 4.34 & 3.38 & 4.28 & 3.57 & 4.64 & 3.61 & 4.20 & 3.51 & 4.43 & 3.38 & 4.24 & 4.17 & 3.54 \\
\hline & 0.30 & 4.80 & 3.85 & 4.70 & 3.62 & 4.91 & 3.94 & 5.03 & 3.88 & 4.81 & 3.82 & 4.84 & 3.63 & 4.83 & 4.77 & 3.92 \\
\hline & 0.40 & 5.36 & 4.13 & 5.20 & 3.83 & 5.34 & 4.12 & 5.50 & 4.14 & 5.32 & 4.28 & 5.14 & 3.84 & 5.30 & 5.25 & 4.21 \\
\hline & 0.50 & 5.79 & 4.36 & 5.44 & 4.00 & 6.00 & 4.53 & 5.74 & 4.31 & 5.54 & 4.57 & 5.35 & 4.00 & 5.73 & 5.65 & 4.46 \\
\hline \multirow{5}{*}{ Toroid } & 0.10 & 3.18 & 2.78 & 3.80 & 3.01 & 3.26 & 2.85 & 4.04 & 3.26 & & & & & 3.30 & & \\
\hline & 0.20 & 4.21 & 3.51 & 4.36 & 3.40 & 4.32 & 3.60 & 4.66 & 3.64 & & & & & 4.35 & & \\
\hline & 0.30 & 4.86 & 3.90 & 4.72 & 3.64 & 4.97 & 3.98 & 5.06 & 3.91 & & & & & 5.01 & & \\
\hline & 0.40 & 5.43 & 4.19 & 5.22 & 3.85 & 5.41 & 4.17 & 5.53 & 4.17 & & & & & 5.52 & & \\
\hline & 0.50 & 5.87 & 4.43 & 5.47 & 4.01 & 6.10 & 4.60 & 5.78 & 4.34 & & & & & 6.07 & & \\
\hline \multirow{5}{*}{ Ball } & 0.10 & 2.17 & 1.76 & 1.70 & 1.31 & 2.14 & 1.77 & 1.75 & 1.37 & & & & & 2.16 & & \\
\hline & 0.20 & 3.85 & 2.92 & 2.69 & 2.05 & 3.81 & 2.92 & 2.80 & 2.18 & & & & & 3.91 & & \\
\hline & 0.30 & 5.19 & 3.84 & 3.50 & 2.63 & 5.10 & 3.77 & 3.63 & 2.73 & & & & & 5.37 & & \\
\hline & 0.40 & 6.25 & 5.60 & 4.18 & 3.10 & 6.08 & 4.46 & 4.34 & 3.29 & & & & & 7.02 & & \\
\hline & 0.50 & 7.16 & 5.12 & 4.80 & 3.51 & 6.94 & 4.96 & 4.96 & 3.71 & $\begin{array}{c}7.65( \\
\text { UB) } \\
7.55( \\
\text { LB) }\end{array}$ & & & & 7.50 & & \\
\hline
\end{tabular}

a,b Fully mobilised vertical capacity under $200 \mathrm{kPa}$ and 0.001 surcharge;

c,d,e,f Sources of solution: Upper bound solutions of pipe from Randolph and White (2008); ball from Randolph et al. (2000); FE solutions of pipe, toroid and 
ball from Yan et al. (2011); FE solution for PIP (push-in-place) pipe results from Merifield et al. (2009). 
Table 3 Values of $\boldsymbol{T}_{50}$ and constant $\boldsymbol{m}$ of hyperbolic fits to invert pore pressure dissipation

\begin{tabular}{|c|c|c|c|c|c|c|c|c|}
\hline \multirow{3}{*}{$\begin{array}{l}\text { Initial } \\
\text { embedment, } w / D\end{array}$} & \multicolumn{4}{|c|}{ Rough objects } & \multicolumn{4}{|c|}{ Smooth objects } \\
\hline & \multicolumn{2}{|c|}{ Pipe (toroid) } & \multicolumn{2}{|c|}{ Ball } & \multicolumn{2}{|c|}{ Pipe (Toroid) } & \multicolumn{2}{|c|}{ Ball } \\
\hline & $T_{50}$ & $m$ & $T_{50}$ & $m$ & $T_{50}$ & $m$ & $T_{50}$ & $m$ \\
\hline 0.1 & $\begin{array}{c}0.028 \\
(0.032)\end{array}$ & 1.05 & 0.012 & 1.3 & $\begin{array}{c}0.022 \\
(0.022)\end{array}$ & 1.05 & 0.005 & 1.3 \\
\hline 0.2 & $\begin{array}{c}0.055 \\
(0.058) \\
\end{array}$ & 1.05 & 0.018 & 1.3 & $\begin{array}{c}0.040 \\
(0.040) \\
\end{array}$ & 1.05 & 0.012 & 1.3 \\
\hline 0.3 & $\begin{array}{c}0.072 \\
(0.070)\end{array}$ & 1.05 & 0.026 & 1.3 & $\begin{array}{c}0.056 \\
(0.056)\end{array}$ & 1.05 & 0.018 & 1.3 \\
\hline 0.4 & $\begin{array}{c}0.095 \\
(0.095) \\
\end{array}$ & 1.05 & 0.032 & 1.3 & $\begin{array}{c}0.072 \\
(0.072) \\
\end{array}$ & 1.05 & 0.025 & 1.3 \\
\hline 0.5 & $\begin{array}{c}0.110 \\
(0.110)\end{array}$ & 1.05 & 0.042 & 1.3 & $\begin{array}{c}0.082 \\
(0.084)\end{array}$ & 1.05 & 0.033 & 1.3 \\
\hline
\end{tabular}




\section{Table 4 Operative $c_{v}$ for different initial embedment values}

\begin{tabular}{|c|c|c|c|c|c|c|c|c|}
\hline \multirow{2}{*}{$\begin{array}{l}\text { Initial } \\
\text { embedment, } w / D\end{array}$} & \multicolumn{2}{|c|}{$\chi=c_{\mathrm{v}, \text { operative }} / C_{\mathrm{v}, \text { invert }}$} & \multicolumn{2}{|c|}{$\begin{array}{c}\text { Depth of operative } c_{v} \\
\text { (normalised by object } \\
\text { diameter) }\end{array}$} & \multicolumn{2}{|c|}{$\chi=C_{\mathrm{v}, \text { operative }} / C_{\mathrm{v}, \text { invert }}$} & \multicolumn{2}{|c|}{$\begin{array}{c}\text { Depth of operative } c_{v} \\
\text { (normalised by object } \\
\text { diameter) }\end{array}$} \\
\hline & $\begin{array}{l}\text { Smooth pipe } \\
\text { (toroid) }\end{array}$ & $\begin{array}{l}\text { Rough pipe } \\
\text { (toroid) }\end{array}$ & $\begin{array}{l}\text { Smooth pipe } \\
\text { (toroid) }\end{array}$ & $\begin{array}{l}\text { Rough pipe } \\
\text { (toroid) }\end{array}$ & Smooth ball & Rough ball & Smooth ball & Rough ball \\
\hline 0.1 & 2.60 & 4.20 & 0.28 & 0.46 & 2.60 & 4.20 & 0.28 & 0.46 \\
\hline 0.2 & 2.70 & 3.00 & 0.58 & 0.64 & 2.70 & 3.00 & 0.58 & 0.64 \\
\hline 0.3 & 2.60 & 3.00 & 0.84 & 0.98 & 2.60 & 3.00 & 0.84 & 0.98 \\
\hline 0.4 & 2.40 & 2.80 & 1.02 & 1.20 & 2.40 & 2.40 & 1.02 & 1.02 \\
\hline 0.5 & 2.50 & 2.80 & 1.33 & 1.50 & 2.80 & 2.80 & 1.50 & 1.50 \\
\hline
\end{tabular}


Table 5 Values of $\boldsymbol{T}_{50}$ and constant $\boldsymbol{n}$ of exponents fits to periphery pore pressure dissipation

\begin{tabular}{|c|c|c|c|c|c|c|c|c|}
\hline \multirow{3}{*}{$\begin{array}{l}\text { Initial } \\
\text { embedment, } w / D\end{array}$} & \multicolumn{4}{|c|}{ Rough objects } & \multicolumn{4}{|c|}{ Smooth objects } \\
\hline & \multicolumn{2}{|c|}{ Pipe (Toroid) } & \multicolumn{2}{|c|}{ Ball } & \multicolumn{2}{|c|}{ Pipe (Toroid) } & \multicolumn{2}{|c|}{ Ball } \\
\hline & $T_{50}$ & $n$ & $T_{50}$ & $n$ & $T_{50}$ & $n$ & $T_{50}$ & $n$ \\
\hline 0.1 & $\begin{array}{c}0.012 \\
(0.014)\end{array}$ & 0.52 & 0.0038 & 0.58 & $\begin{array}{c}0.015 \\
(0.015)\end{array}$ & 0.52 & 0.004 & 0.60 \\
\hline 0.2 & $\begin{array}{c}0.026 \\
(0.027)\end{array}$ & 0.50 & 0.0055 & 0.50 & $\begin{array}{c}0.030 \\
(0.030)\end{array}$ & 0.55 & 0.008 & 0.65 \\
\hline 0.3 & $\begin{array}{c}0.036 \\
(0.035)\end{array}$ & 0.47 & 0.0070 & 0.49 & $\begin{array}{c}0.044 \\
(0.044)\end{array}$ & 0.6 & 0.012 & 0.66 \\
\hline 0.4 & $\begin{array}{c}0.040 \\
(0.040)\end{array}$ & 0.44 & 0.0078 & 0.48 & $\begin{array}{c}0.055 \\
(0.055)\end{array}$ & 0.6 & 0.016 & 0.66 \\
\hline 0.5 & $\begin{array}{c}0.050 \\
(0.050) \\
\end{array}$ & 0.44 & 0.012 & 0.48 & $\begin{array}{c}0.079 \\
(0.080) \\
\end{array}$ & 0.6 & 0.020 & 0.66 \\
\hline
\end{tabular}




\section{Figure captions}

Figure 1 Schematic diagram of problem

Figure 2 Geometry and definitions (pipe case)

Figure 3 Schematic illustration of critical state model and undrained failure criteria

Figure 4 Finite element meshes (Oblique view of models)

Figure 5 Mesh validation: Undrained penetration resistance $(w / D=0.5)$

Figure 6 Excess pore pressure distributions after penetration

Figure 7 Excess pore pressure distributions around object periphery after penetration

Figure 8 Excess pore pressure dissipation time histories at invert for embedded objects

(200 kPa surcharge cases unless otherwise noted)

Figure 9 Average pore pressure dissipation and rise in effective stress around the object periphery

Figure 10 Summary of $T_{50}$ for invert consolidation and average periphery consolidation

Figure 11 Excess pore pressure dissipation time histories at invert for embedded toroid and pipe under varying OLR and $w / D$

Figure 12 Stress path for toroid invert during penetration and consolidation

Figure 13 Comparison of calculated and observed dissipation curves at pipe invert

Figure 14 Excess pore pressure dissipation time histories at invert for smooth pipe and penetrometers in this study compared with CPT, pipe and PPP (Chatterjee et al., 2014) on homogeneous soil 


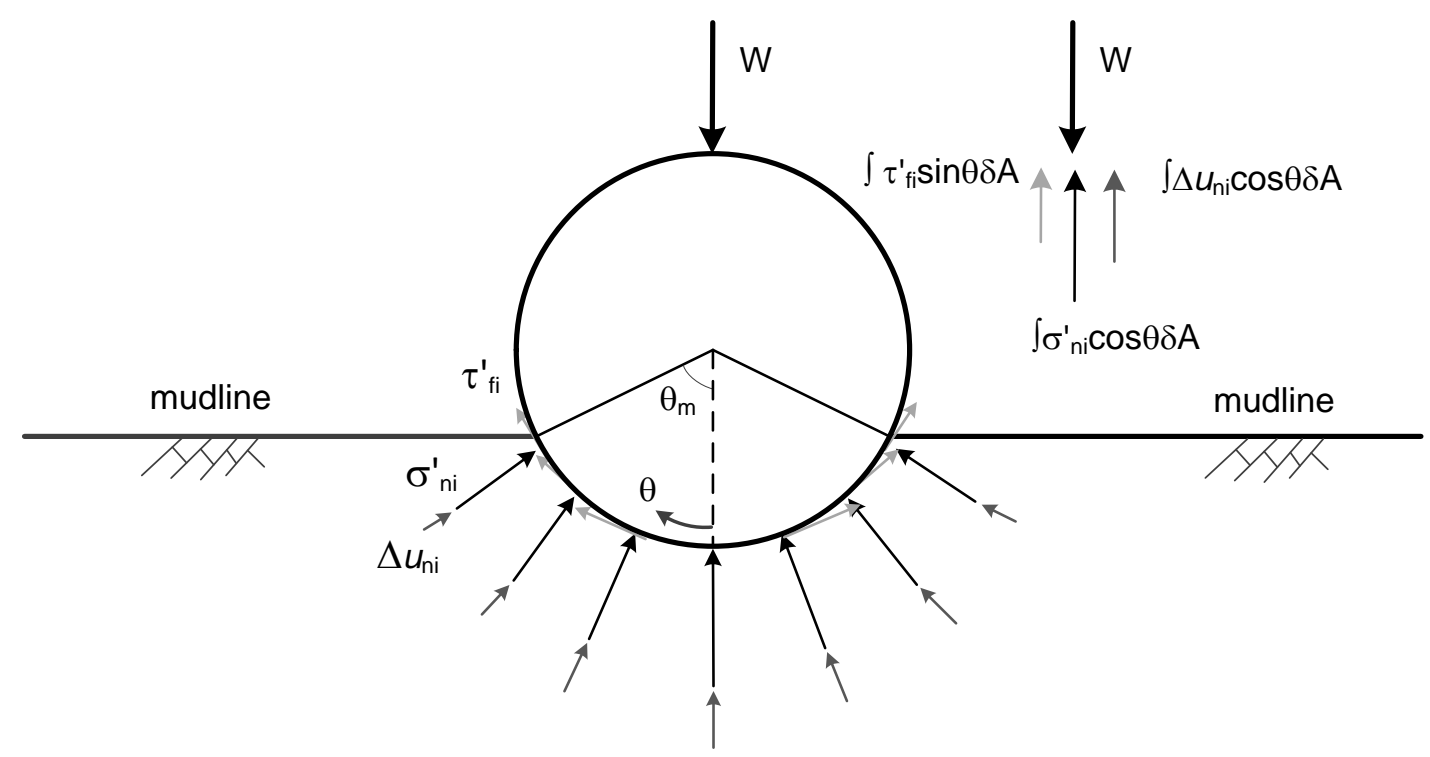

Figure 1 Schematic diagram of problemFigure 1 Schematic diagram of problem 


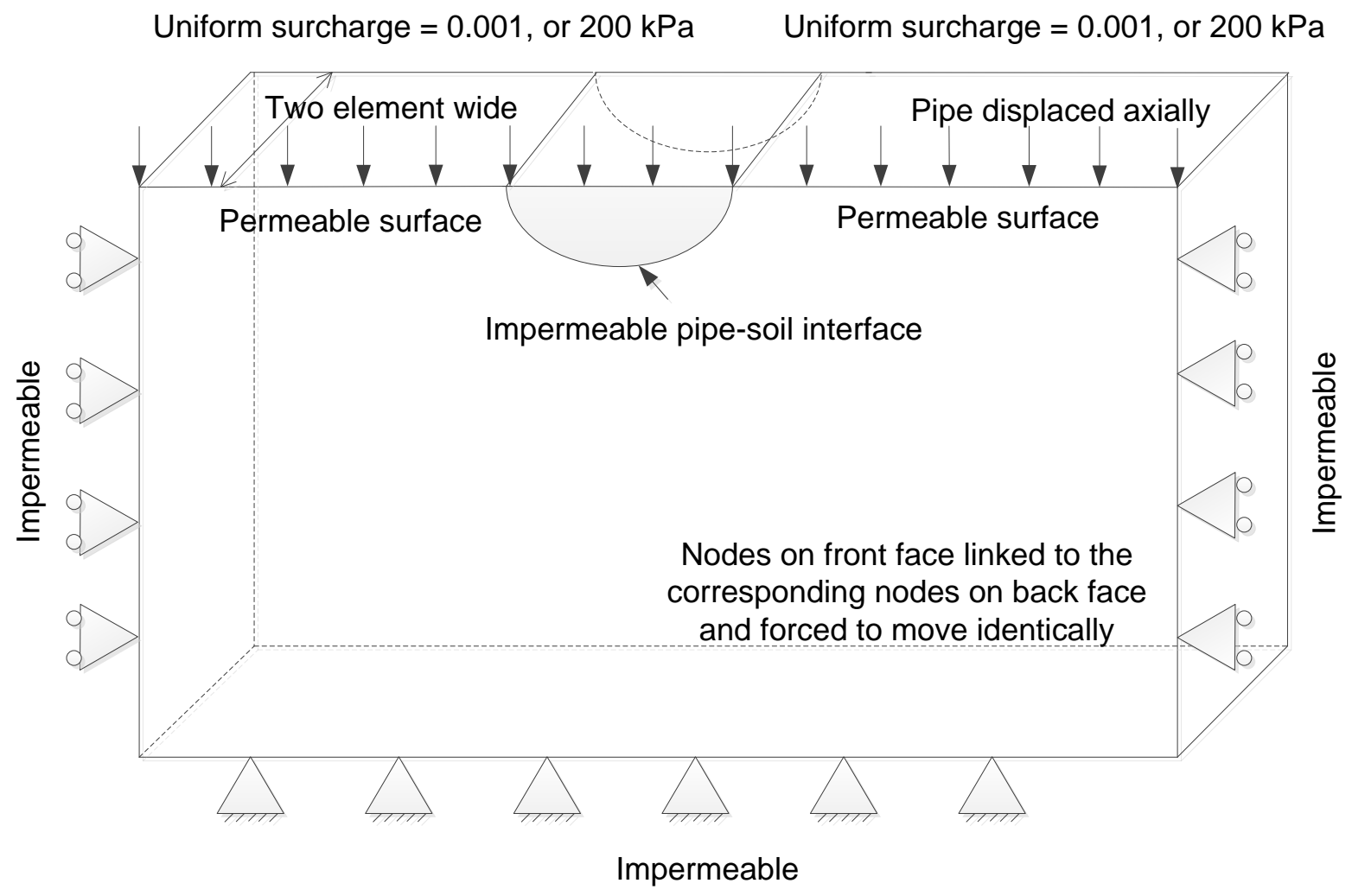

Figure 2 Geometry and definitions (pipe case)Figure 2 Geometry and definitions (pipe case) 

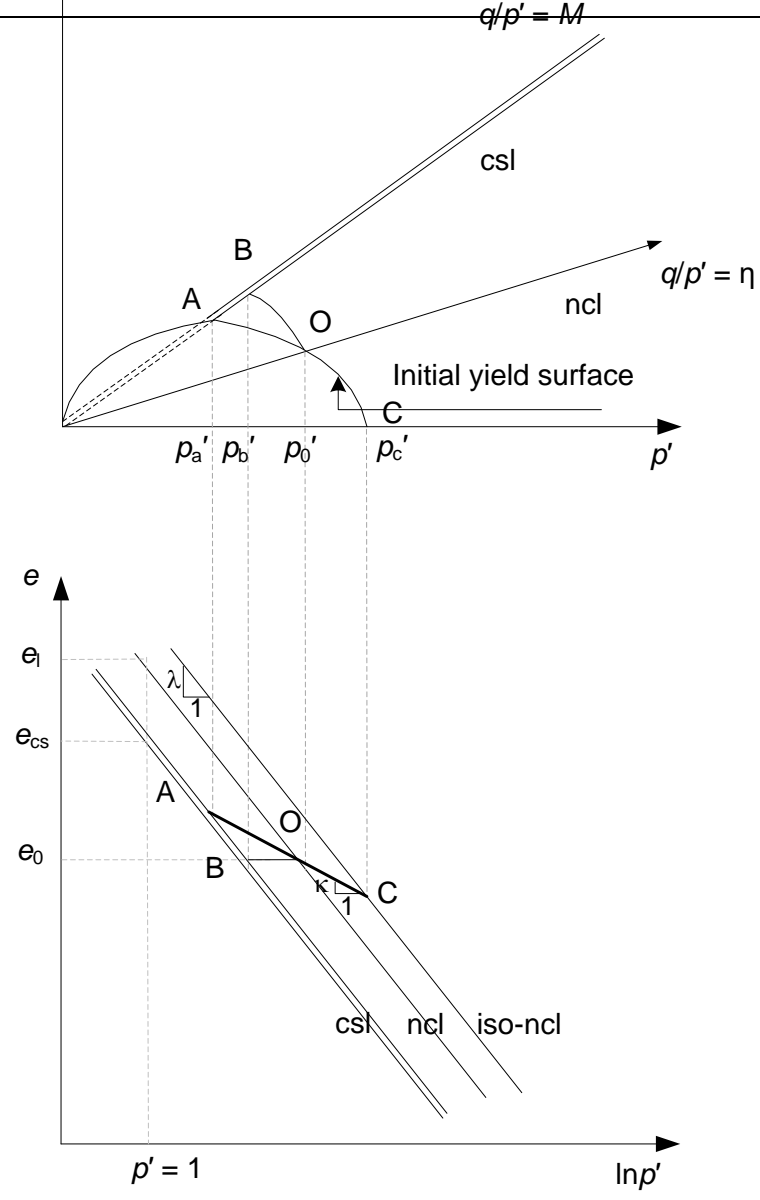

(a)

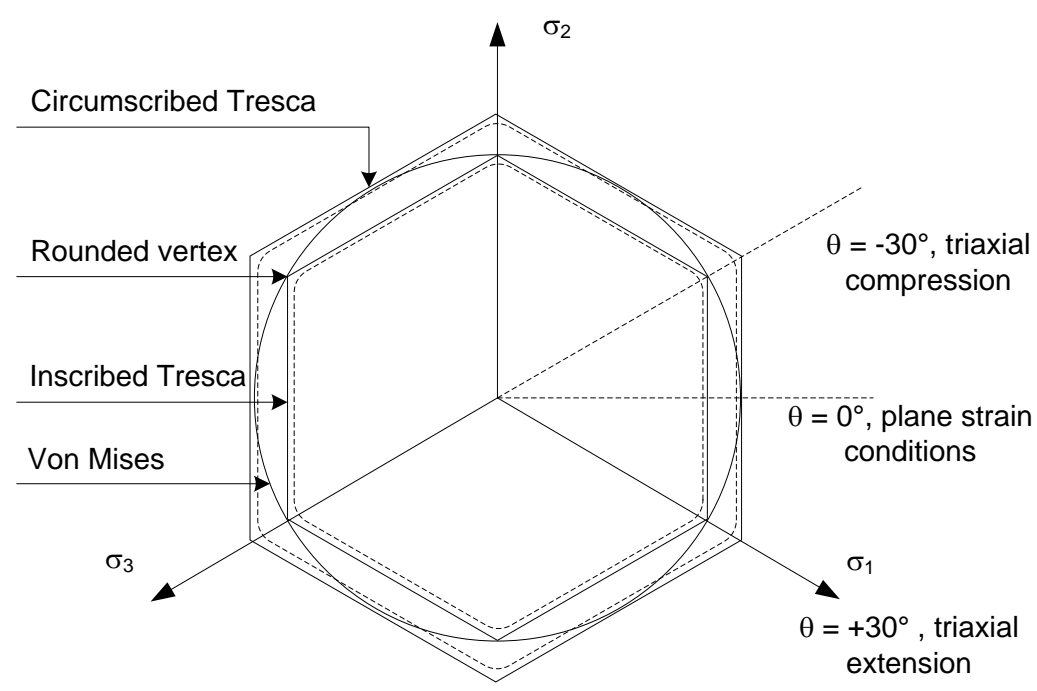

(b)

Figure 3 Schematic illustration of critical state model and undrained failure criteriaFigure 3 Schematic illustration of critical state model and undrained failure criteria 

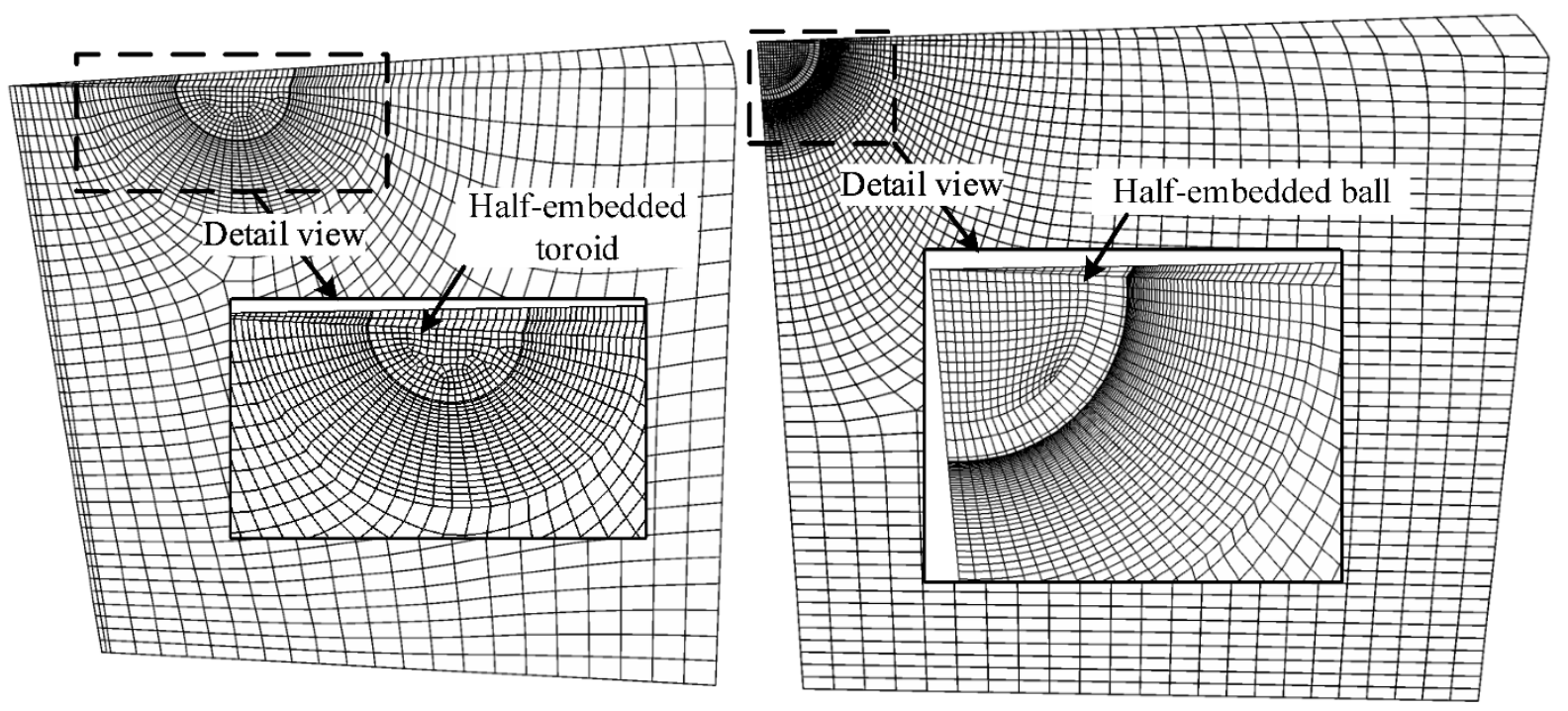

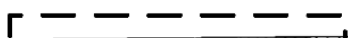

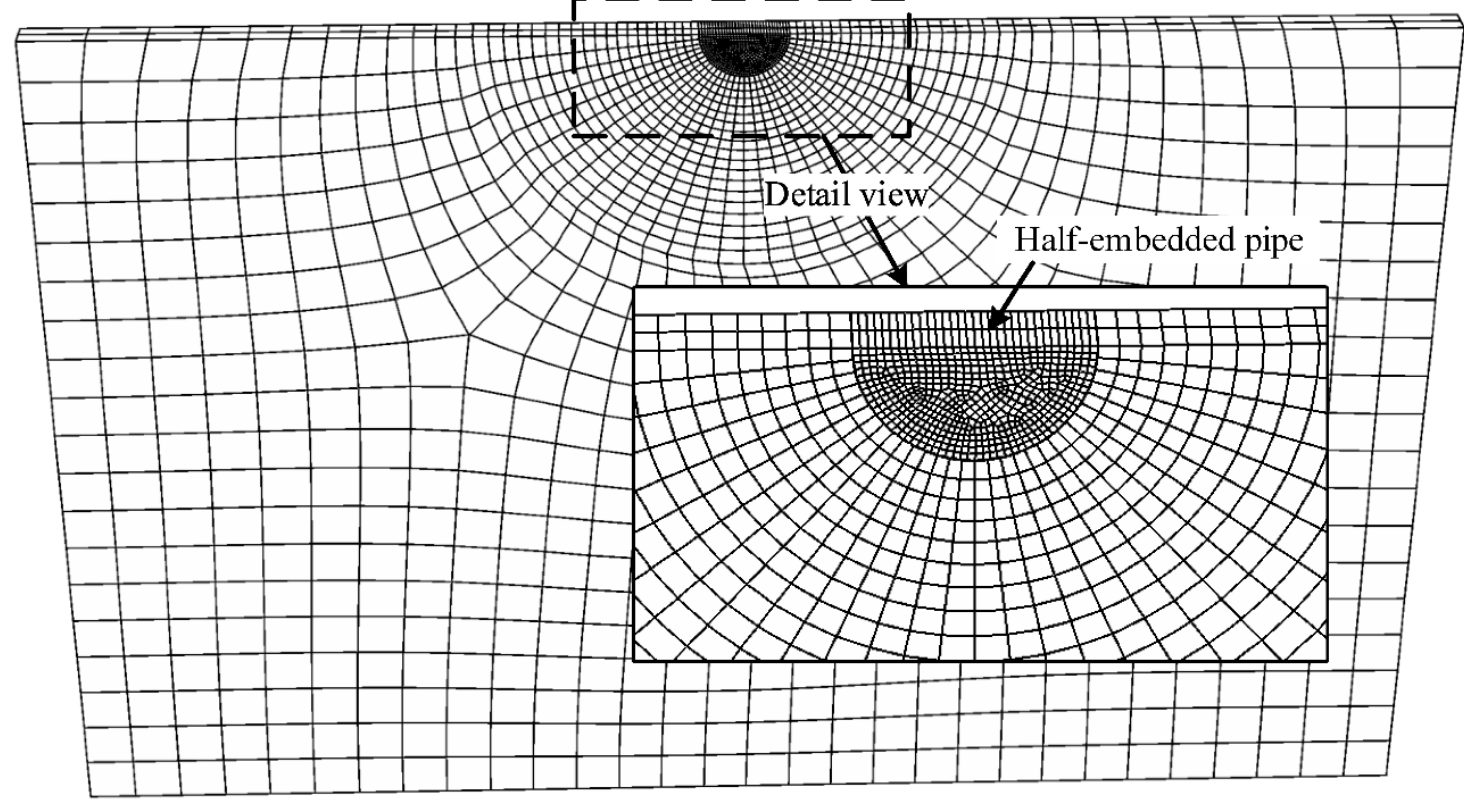

Figure 4 Finite element meshes (Oblique view of models)Figure-4 Finite element meshes

(Oblique view of models) 


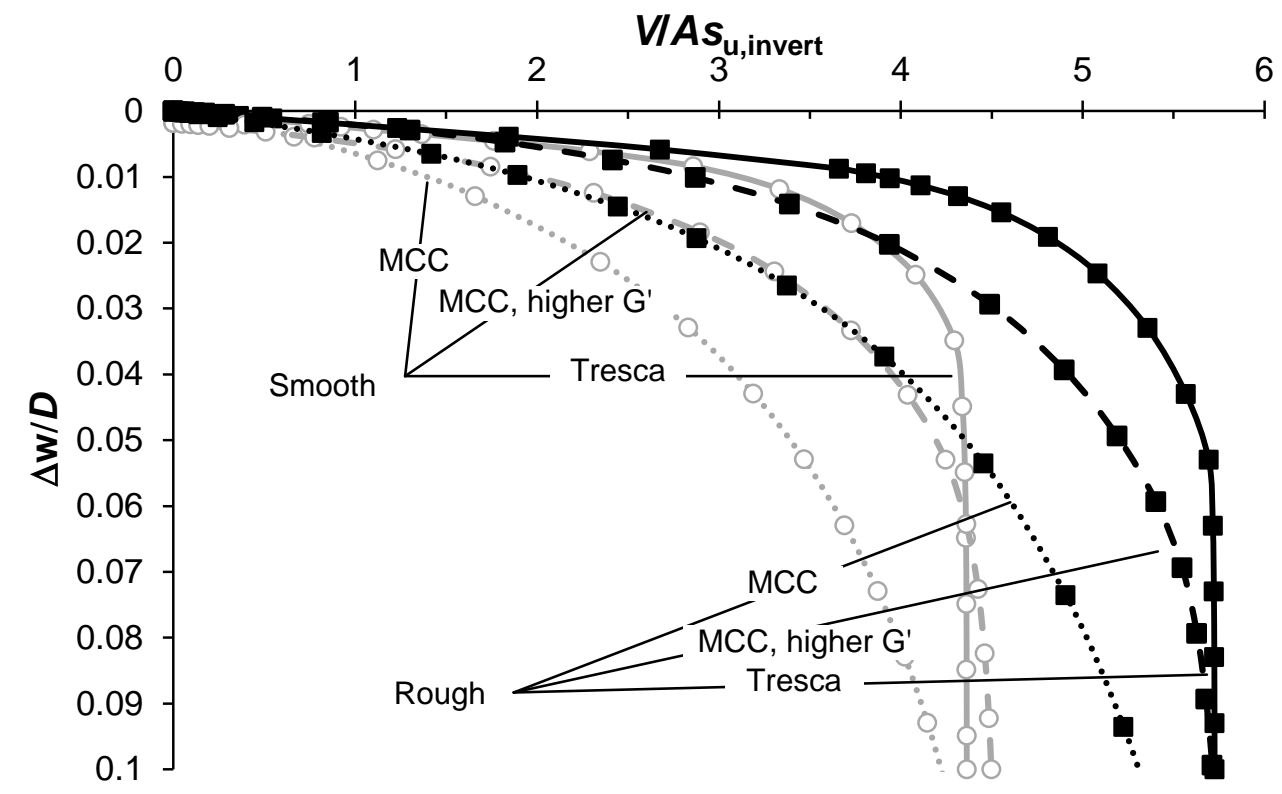

(a) Pipe, homogeneous strength

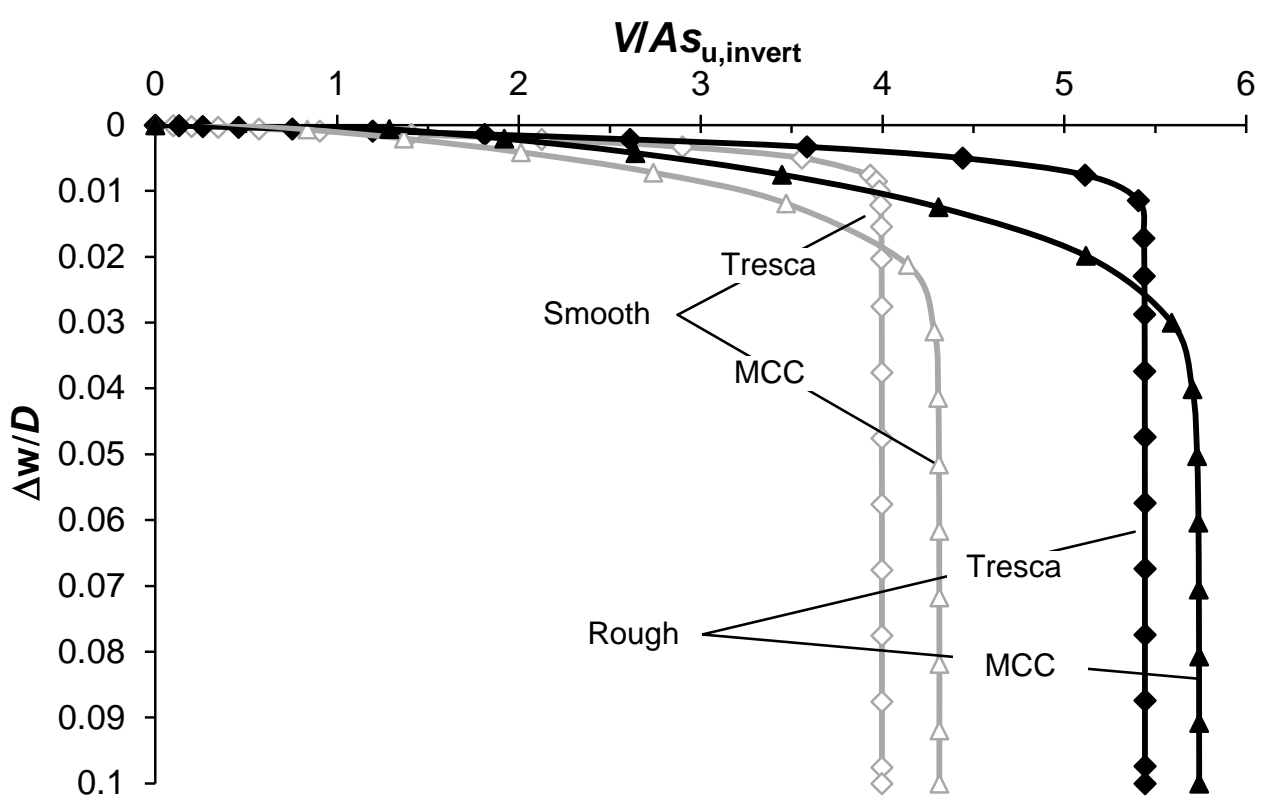

(b) Pipe, proportional strength 


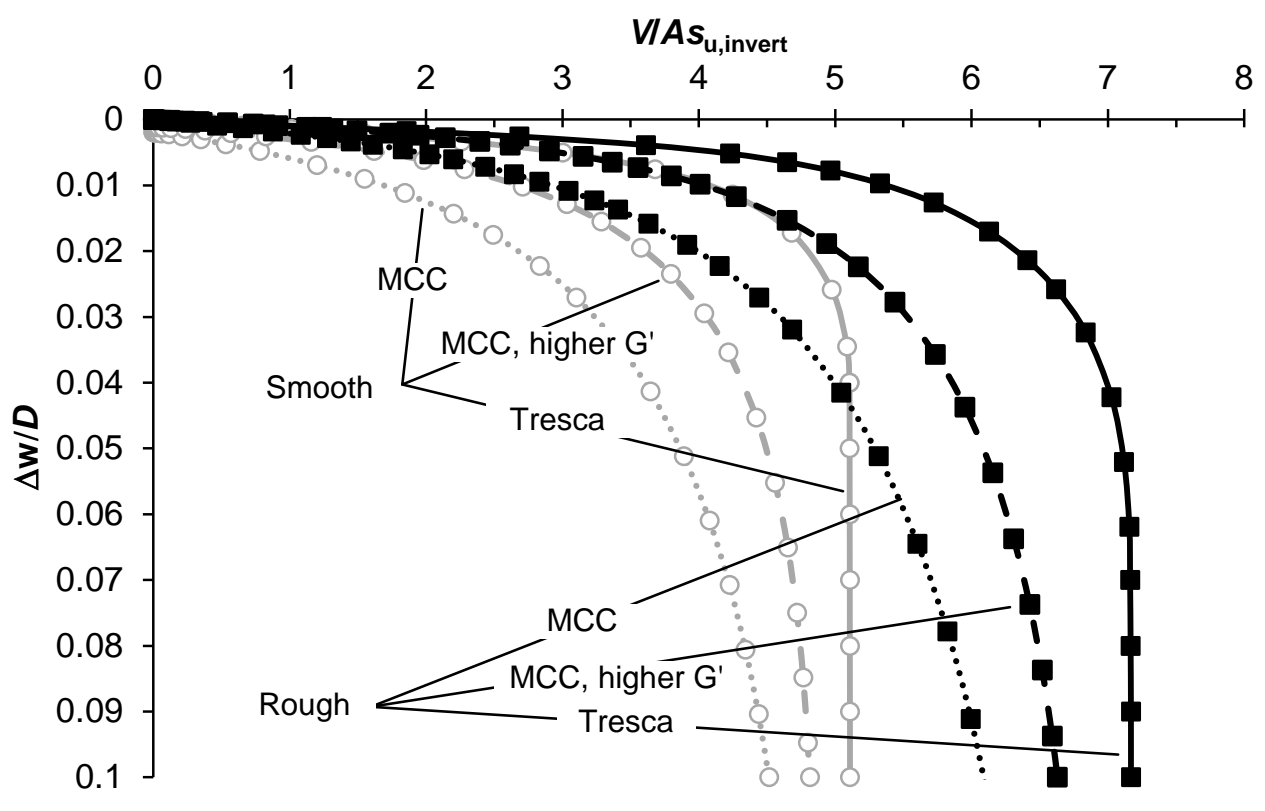

(c) Ball, homogeneous strength

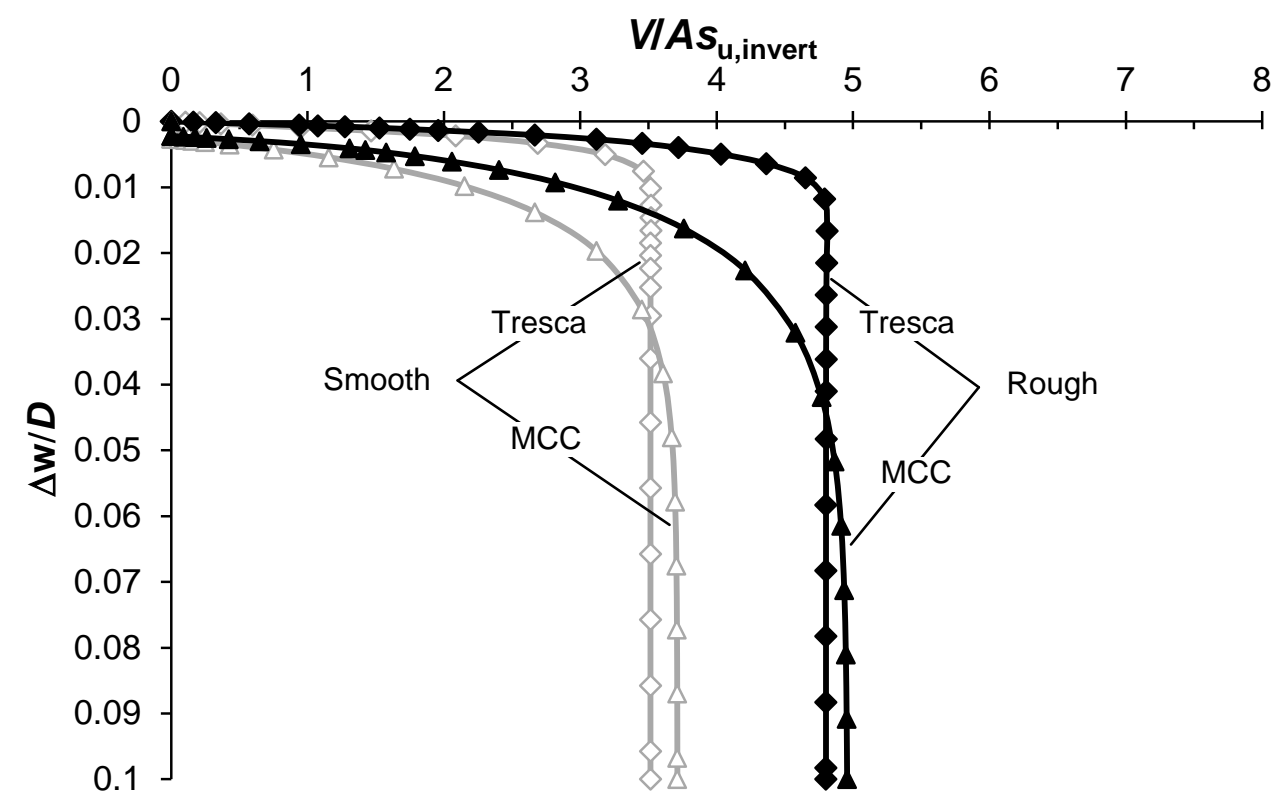

(d) Ball, proportional strength

Figure 5 Mesh validation: Undrained penetration resistance $(w / D=0.5)$ Figure $5 \mathrm{Mesh}$ validation: Undrained penetration resistance $(w / D=0.5)$ 


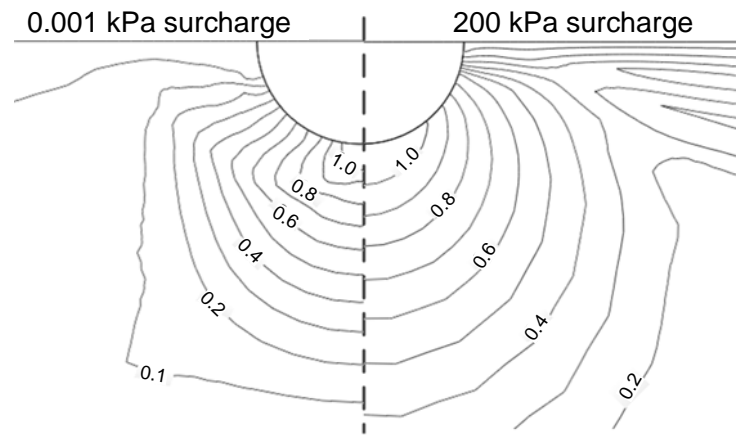

(a) Smooth pipe

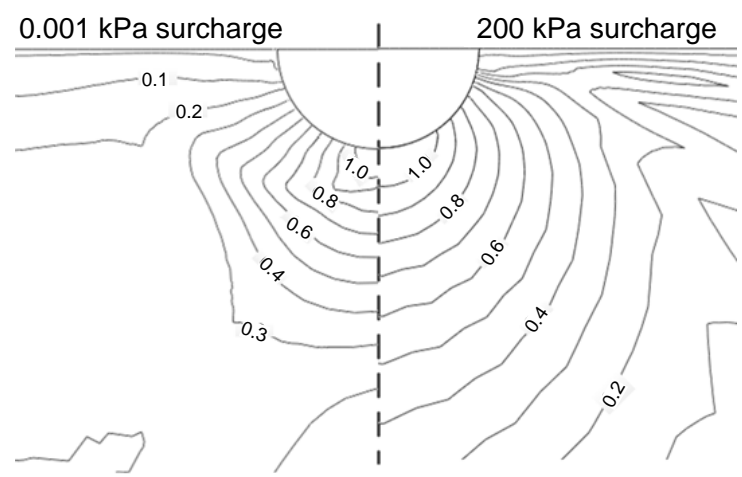

(c) Smooth toroid

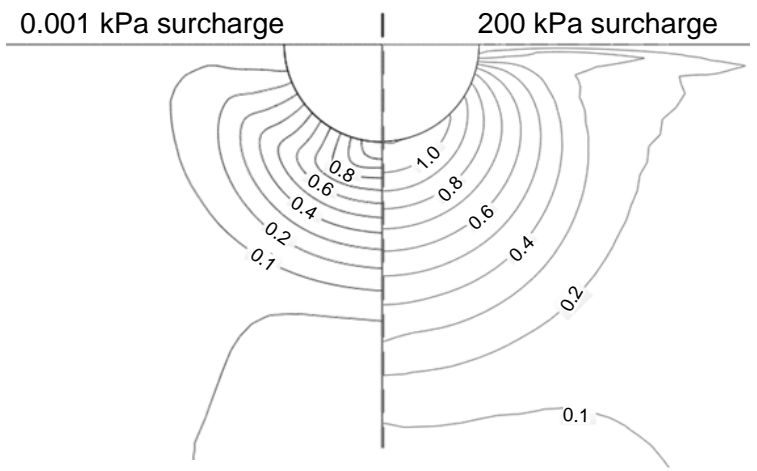

(e) Smooth ball

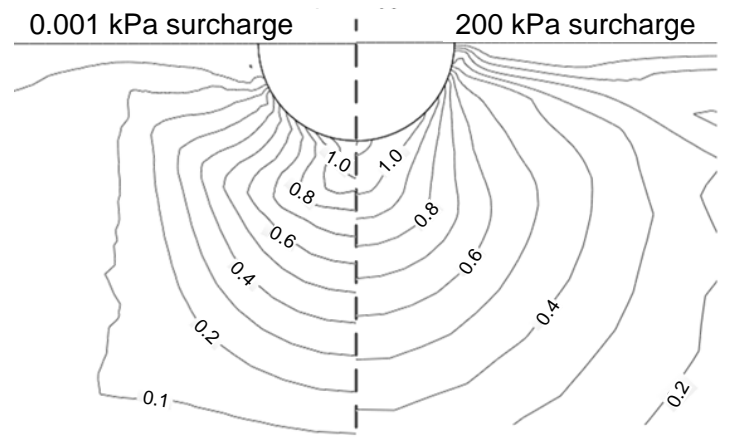

(b) Rough pipe

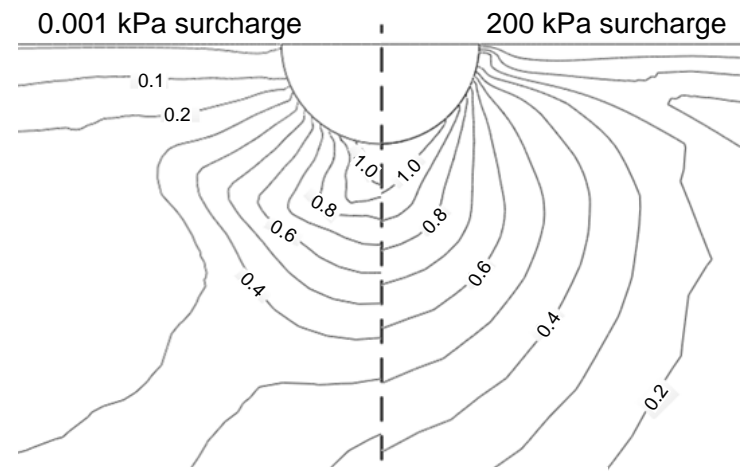

(d) Rough toroid

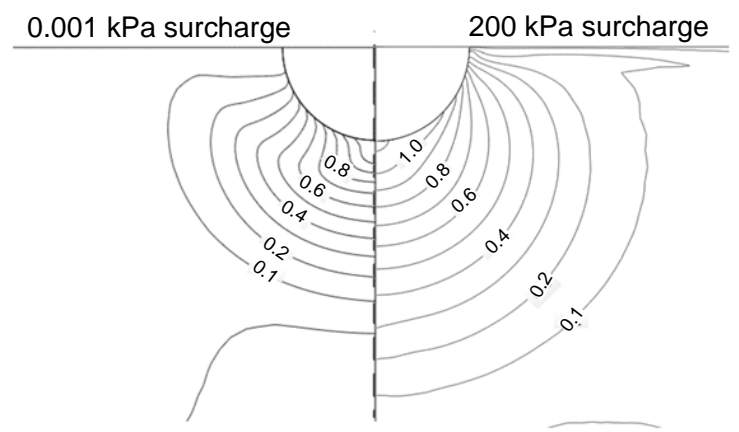

(f) Rough ball

Figure 6 Excess pore pressure distributions after penetrationFigure 6 Excess pere pressure distributions after penetration 


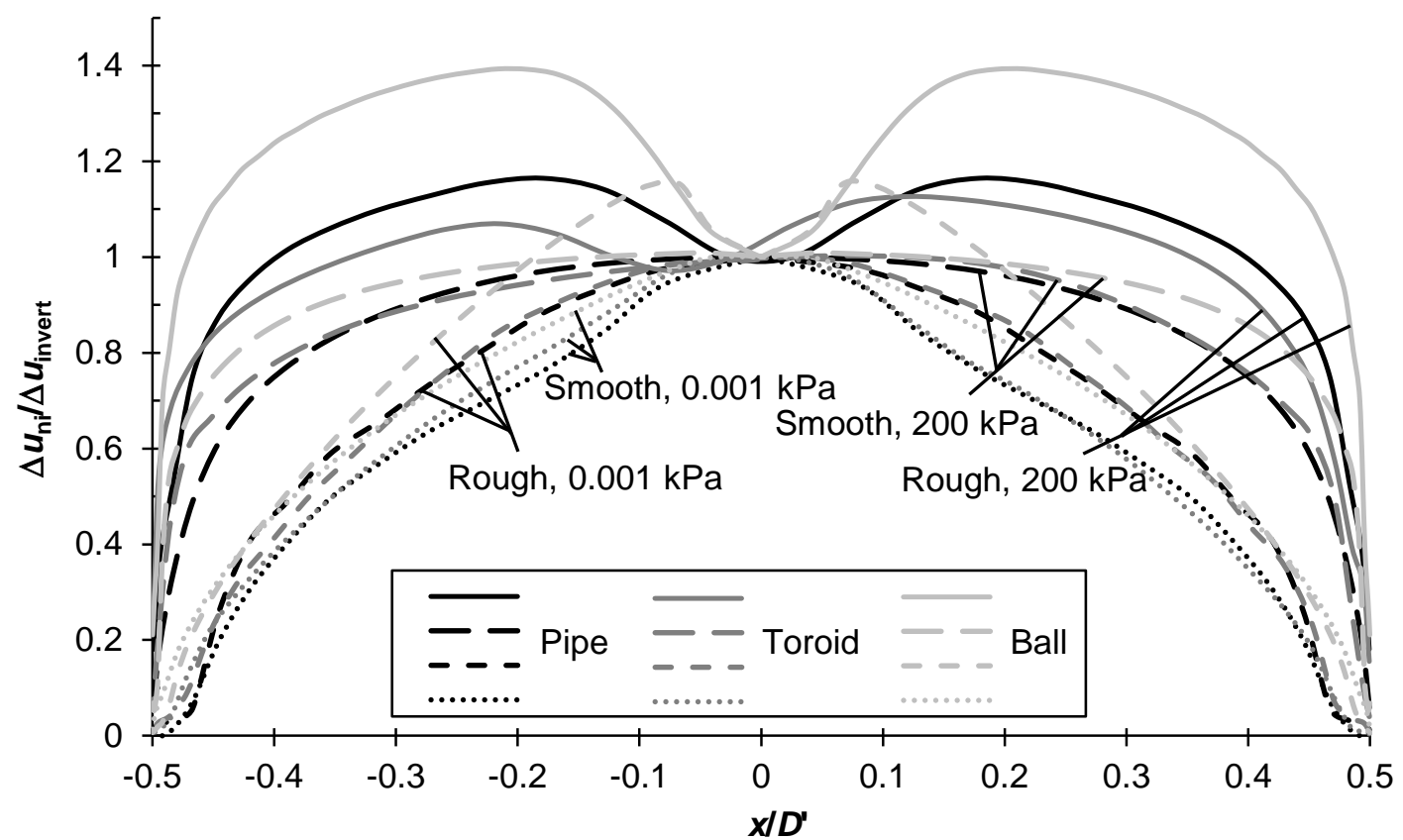

Figure 7 Excess pore pressure distributions around object periphery after penetrationFigure 7

Excess pore pressure distributions around object periphery after penetration 


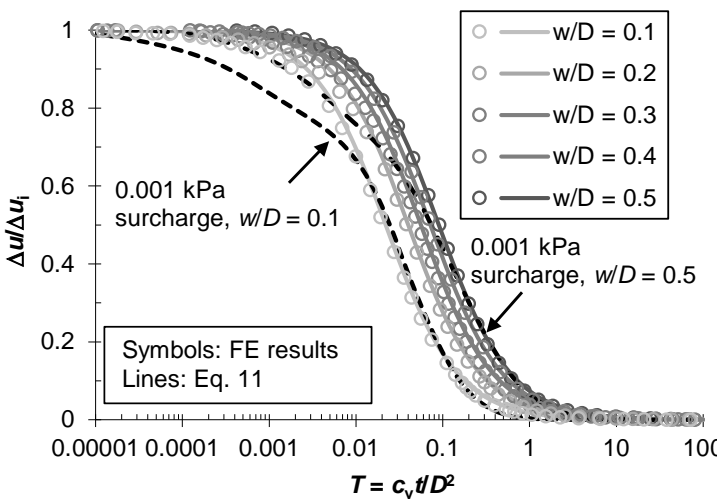

(a) Smooth pipe

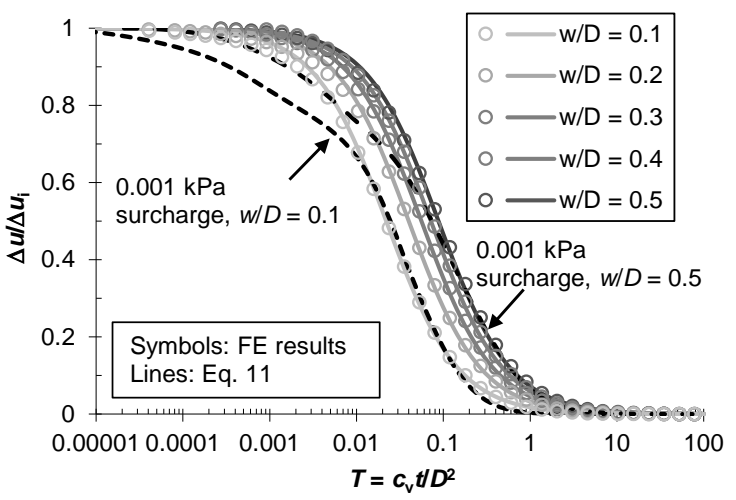

(c) Smooth toroid

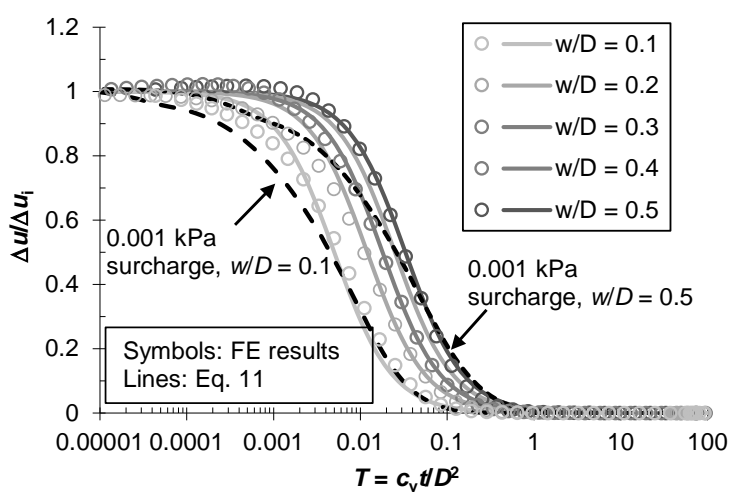

(e) Smooth ball

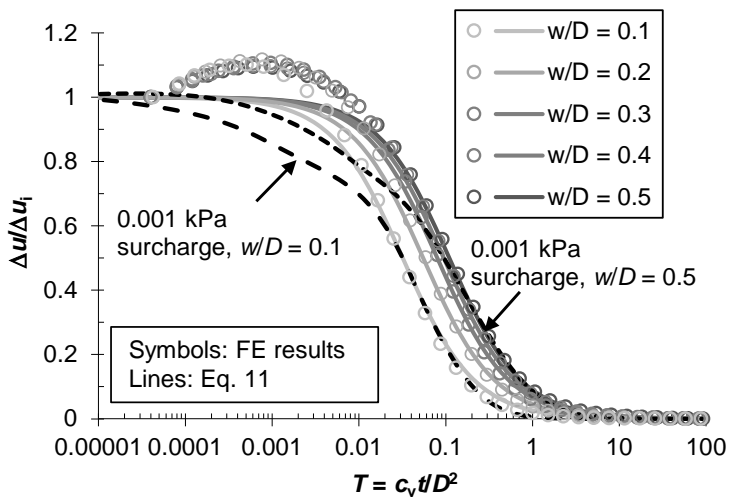

(b) Rough pipe

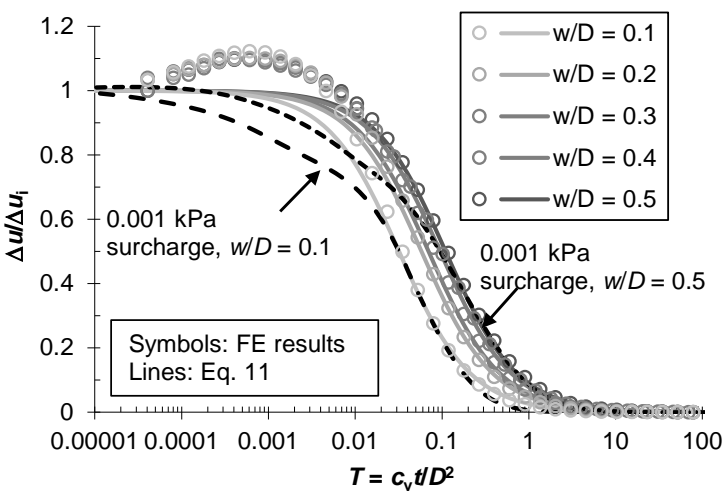

(d) Rough toroid

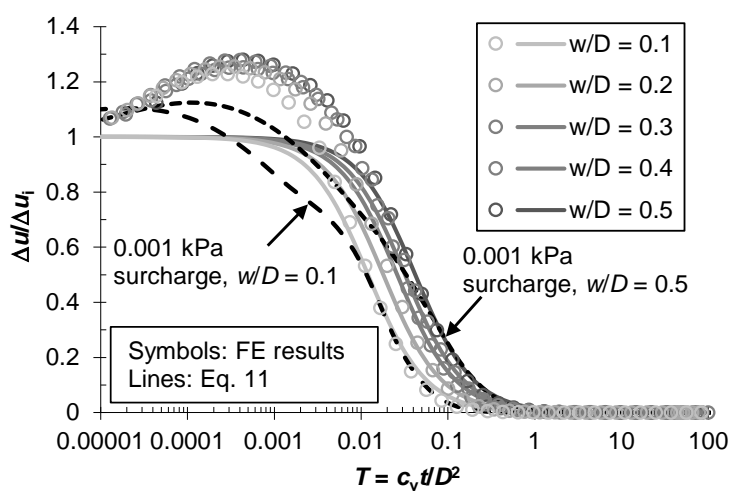

(f) Rough ball

Figure 8 Excess pore pressure dissipation time histories at invert for embedded objects (200 kPa surcharge cases unless otherwise noted)Figure 8 Excess pore pressure dissipation time histories at invert for embedded objects ( $200 \mathrm{kPa}$ surcharge cases mnless otherwise noted) 


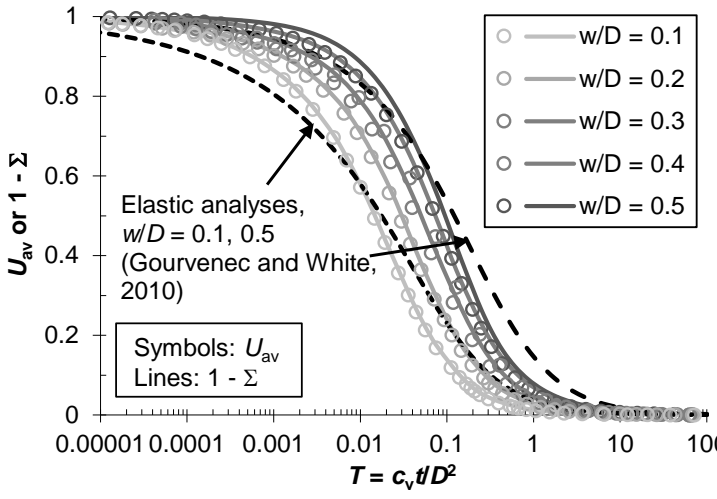

(a) Smooth pipe

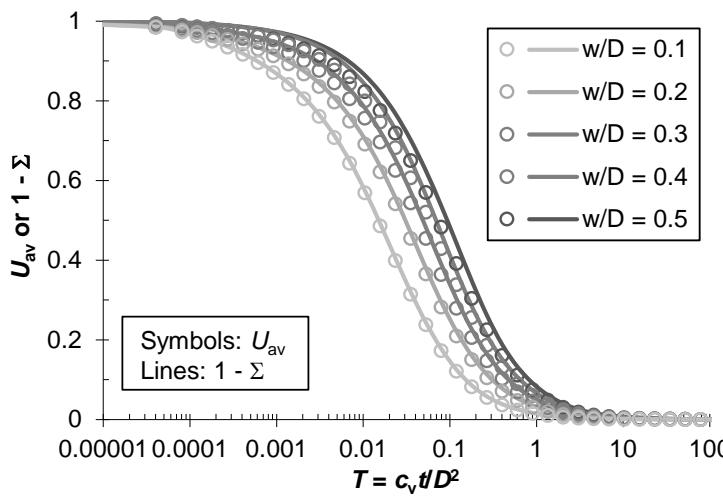

(c) Smooth toroid

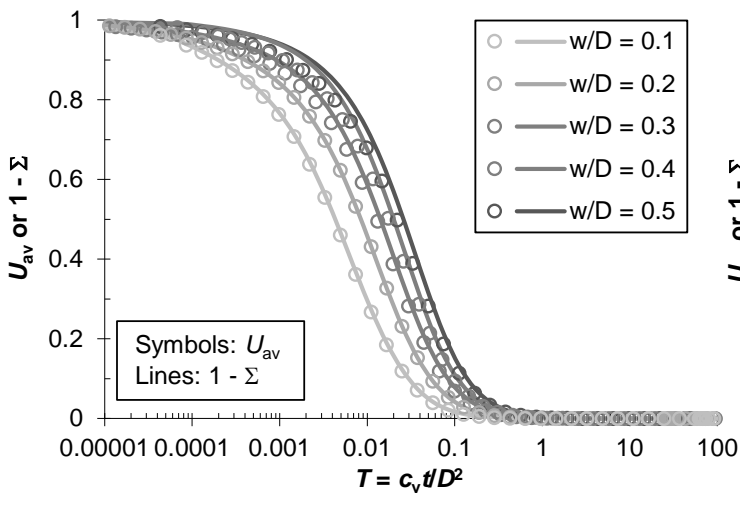

(e) Smooth ball

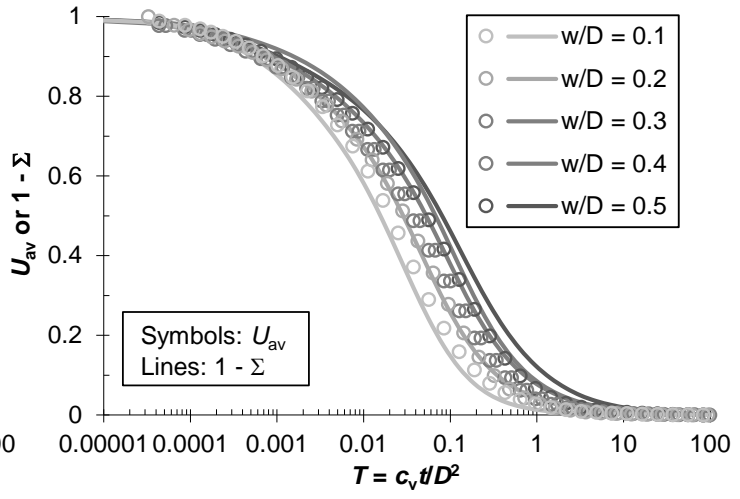

(b) Rough pipe

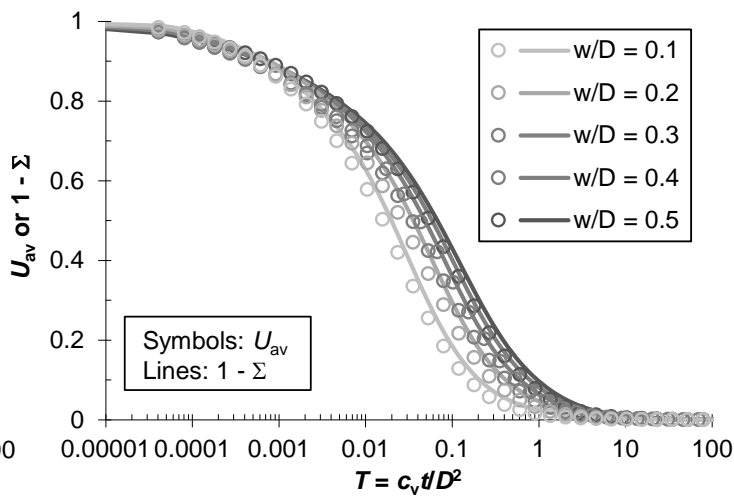

(d) Rough toroid

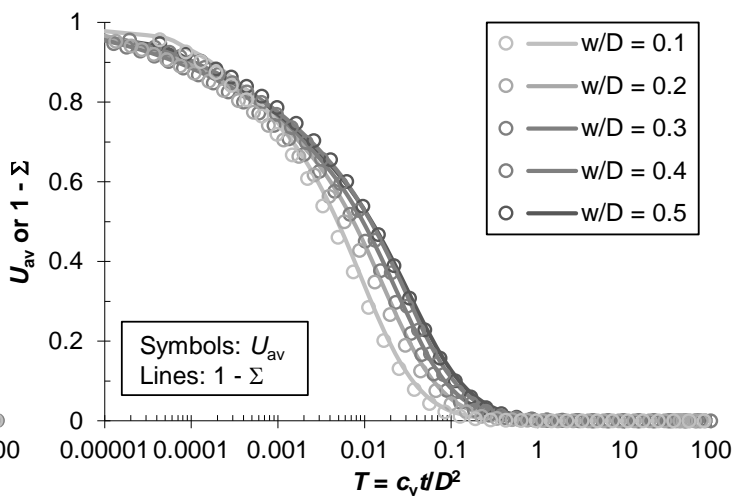

(f) Rough ball

Figure 9 Average pore pressure dissipation and rise in effective stress around the object peripheryFigure 9 Average pore pressure dissipation and rise in effective stress around the object periphery 


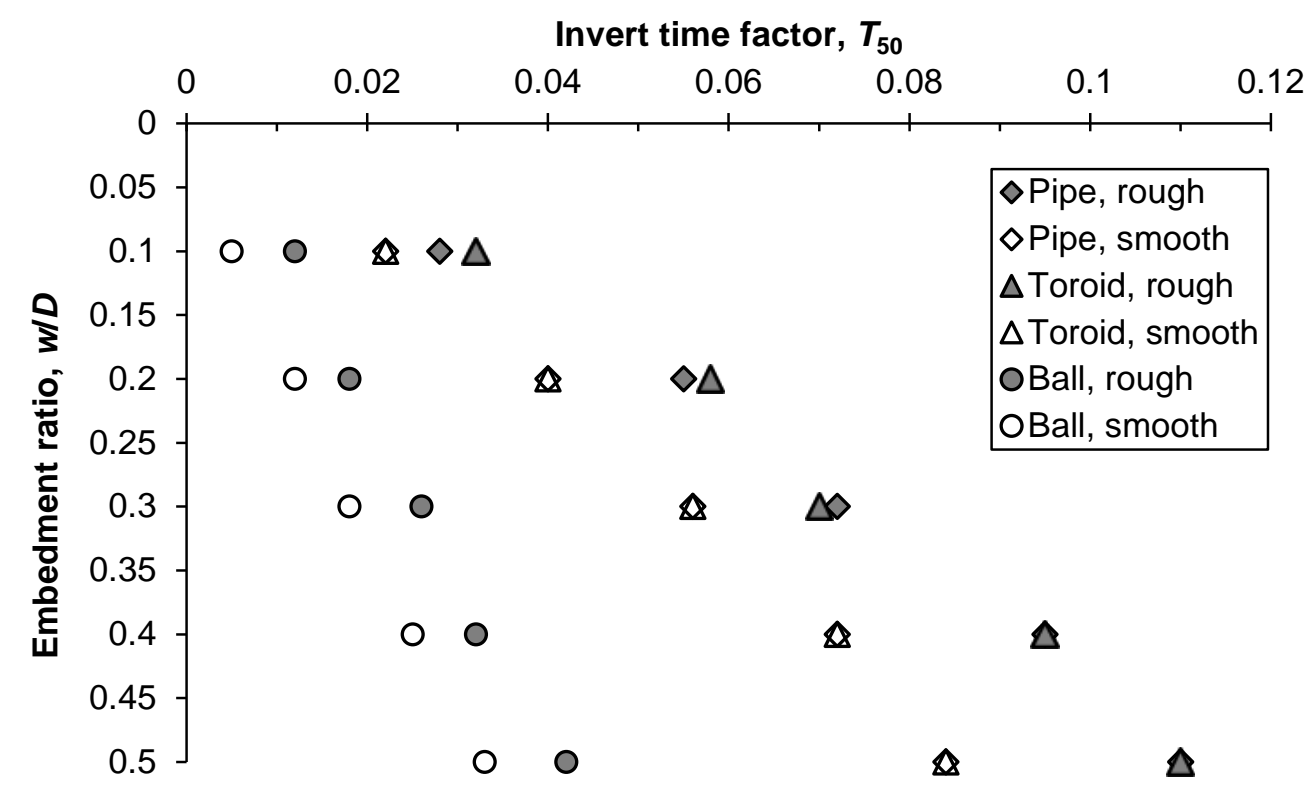

(a) Invert consolidation

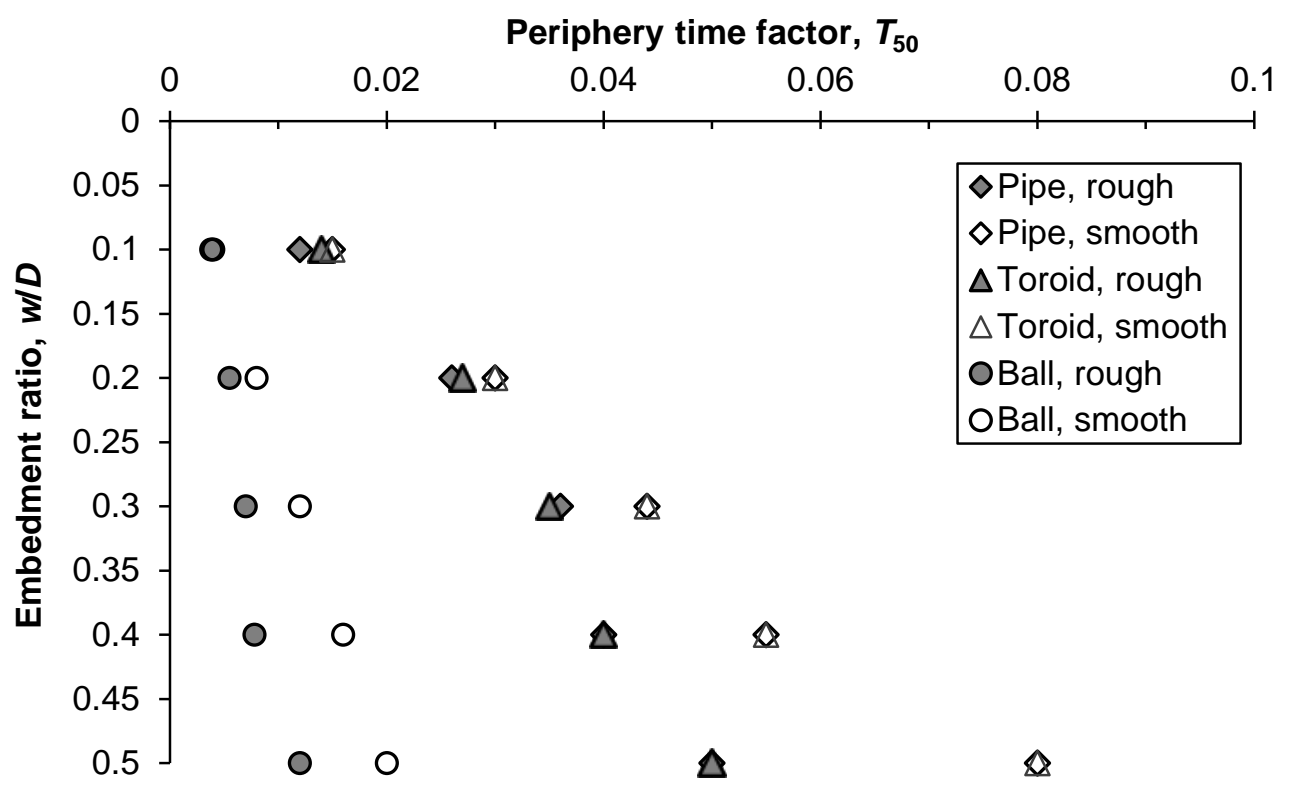

(b) Periphery consolidation

Figure 10 Summary of $T_{50}$ for invert consolidation and average periphery consolidationFigure 10 Summary of $T_{50}$ for invert consolidation and average periphery consolidation 


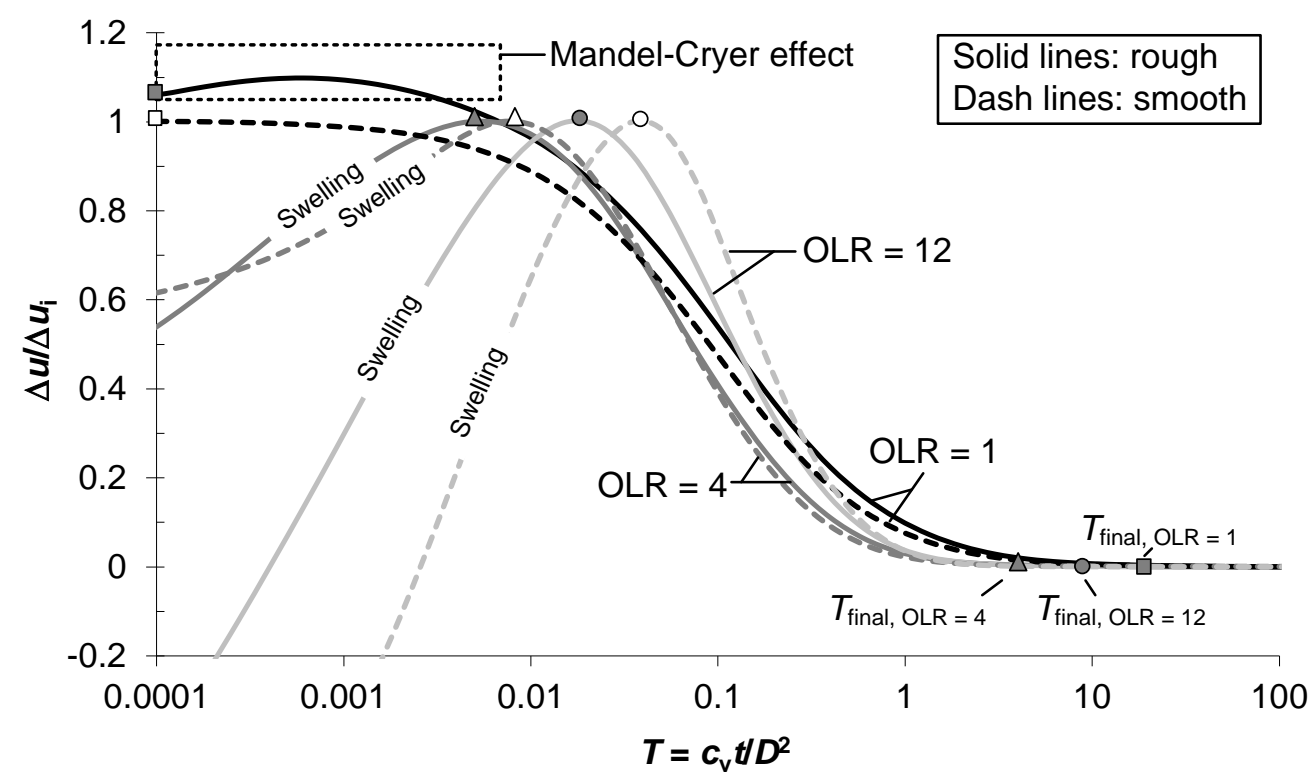

(a) Toroid with different OLR, $w / D=0.5$

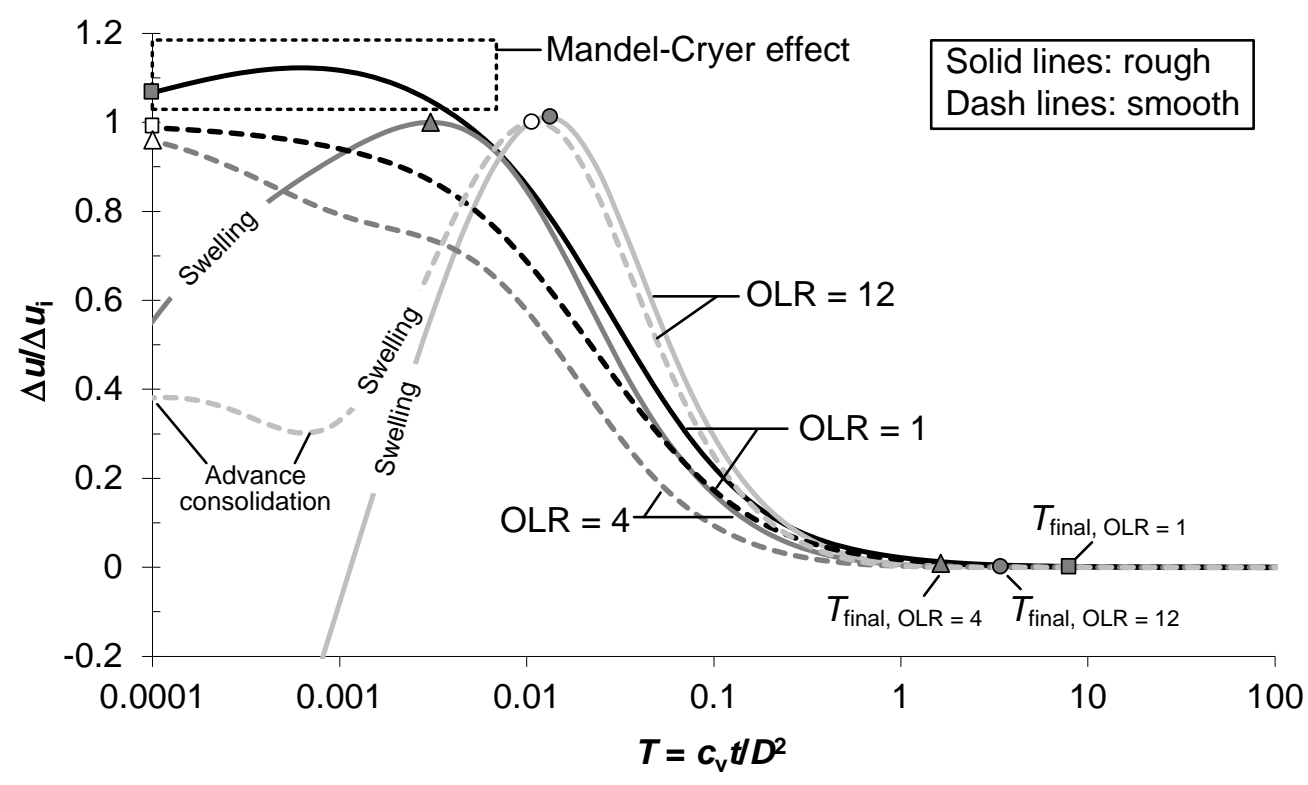

(b) Toroid with different OLR, $w / D=0.1$ 


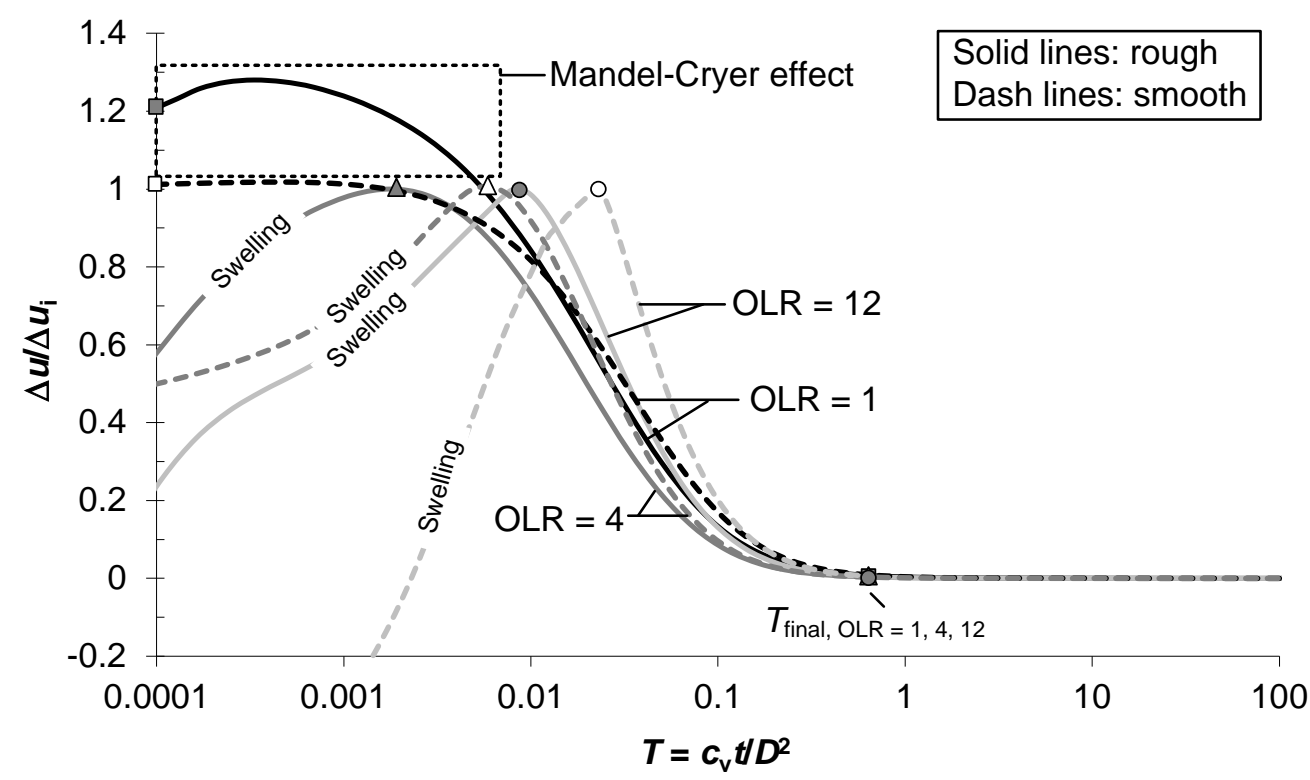

(c) Ball with different OLR, $w / D=0.5$

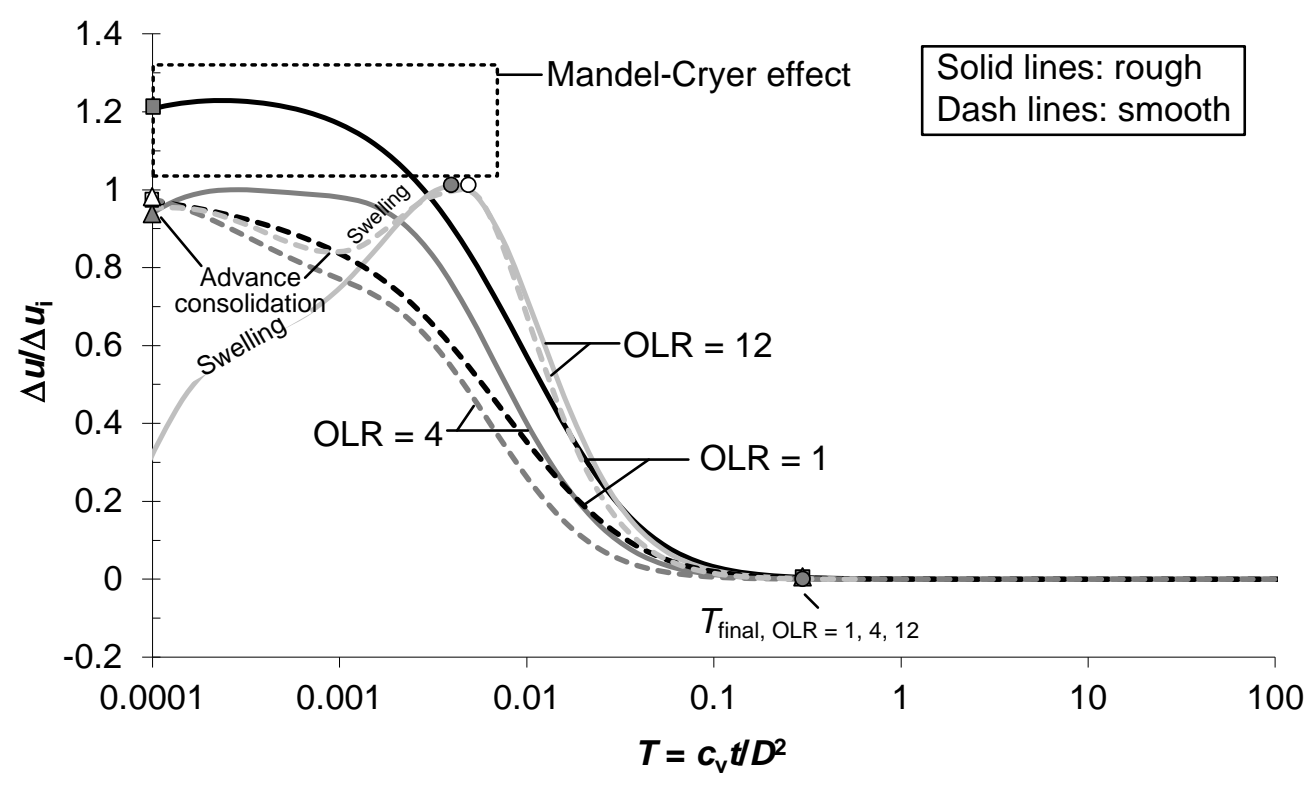

(d) Ball with different OLR, w/D $=0.1$

Figure 11 Excess pore pressure dissipation time histories at invert for embedded toroid and pipe under varying OLR and $w / D$ Figure 11 Excess pore pressure dissipation time histories at invert for embedded toroid and pipe under varying OLR and w/D 


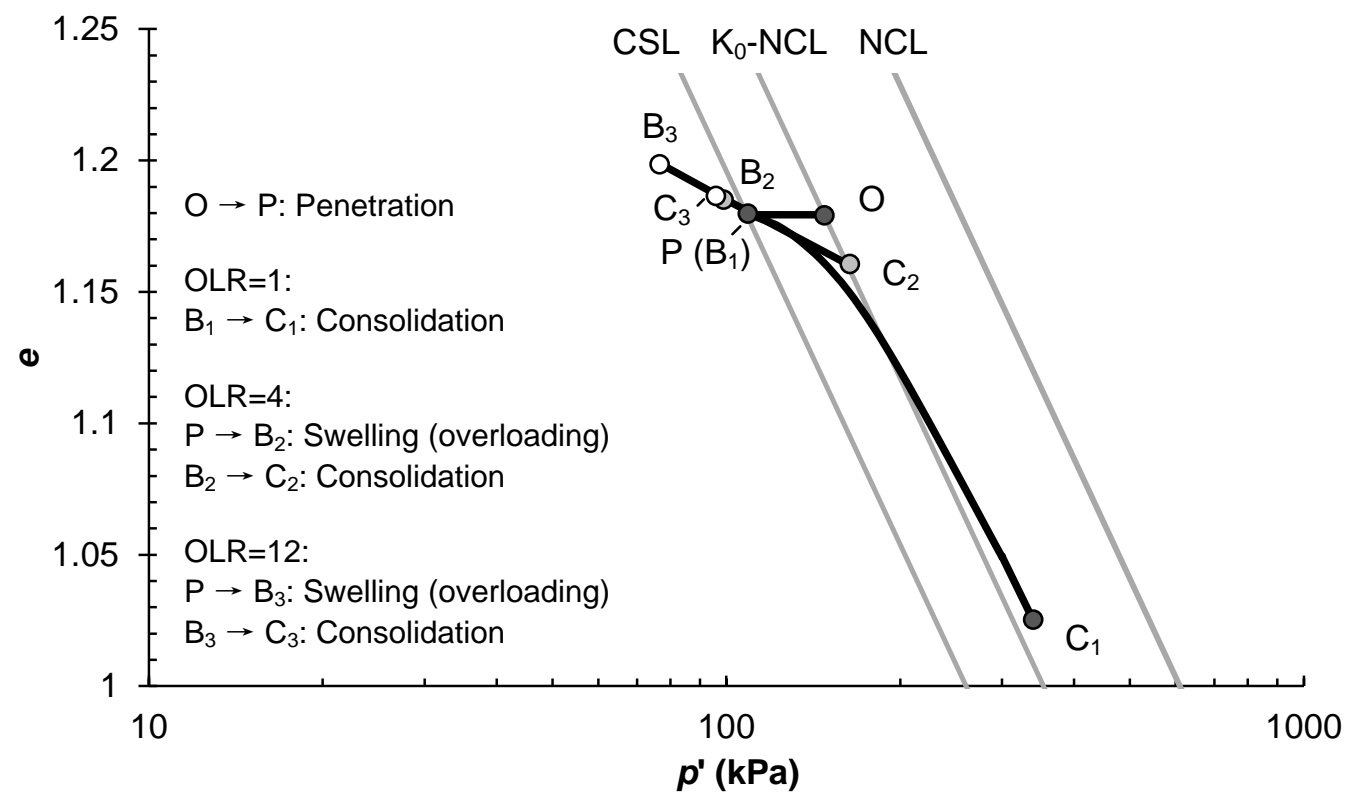

Figure 12 Stress path for toroid invert during penetration and consolidationFigure 12 Stress path for toroid invert during penetration and consolidation 


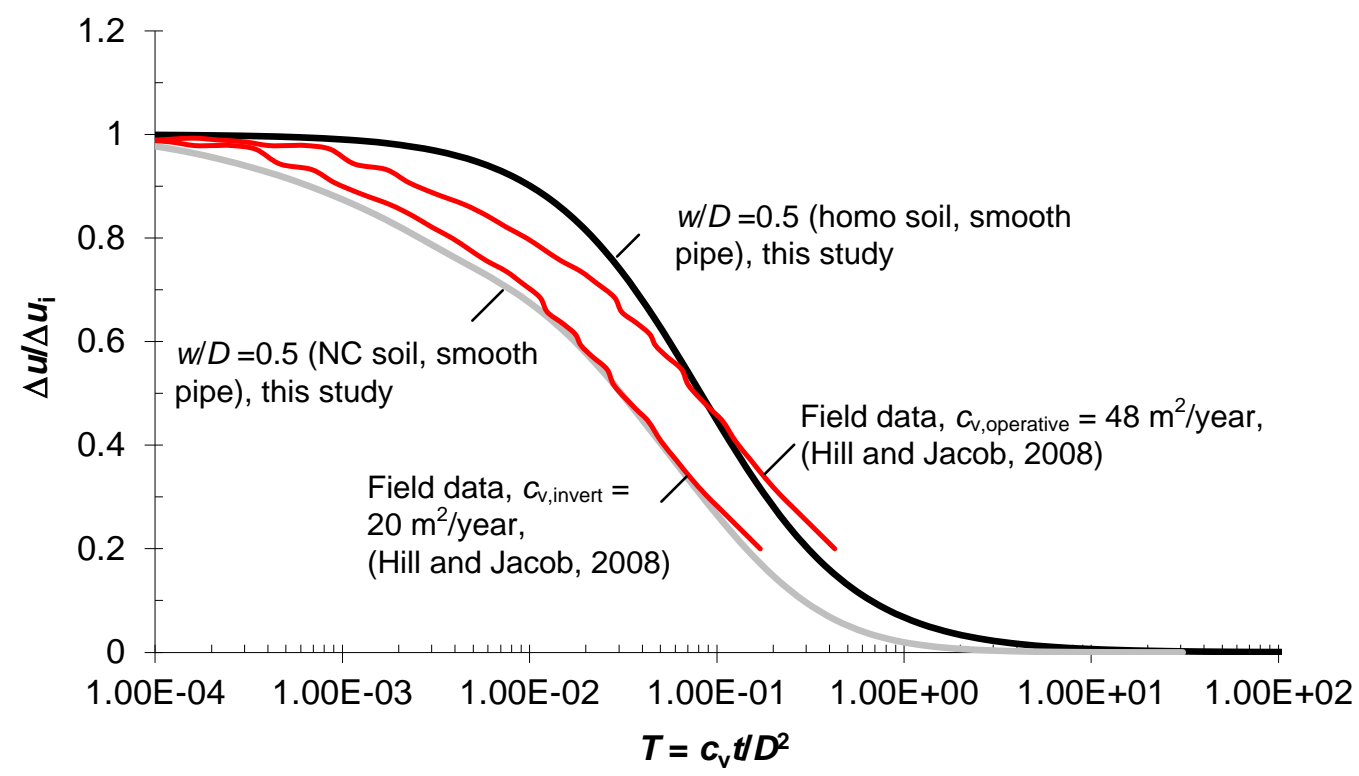

Figure 13 Comparison of calculated and observed dissipation curves at pipe invertFigure 13 Gomparison of calteulated and observed dissipation eurves at pipe invert 


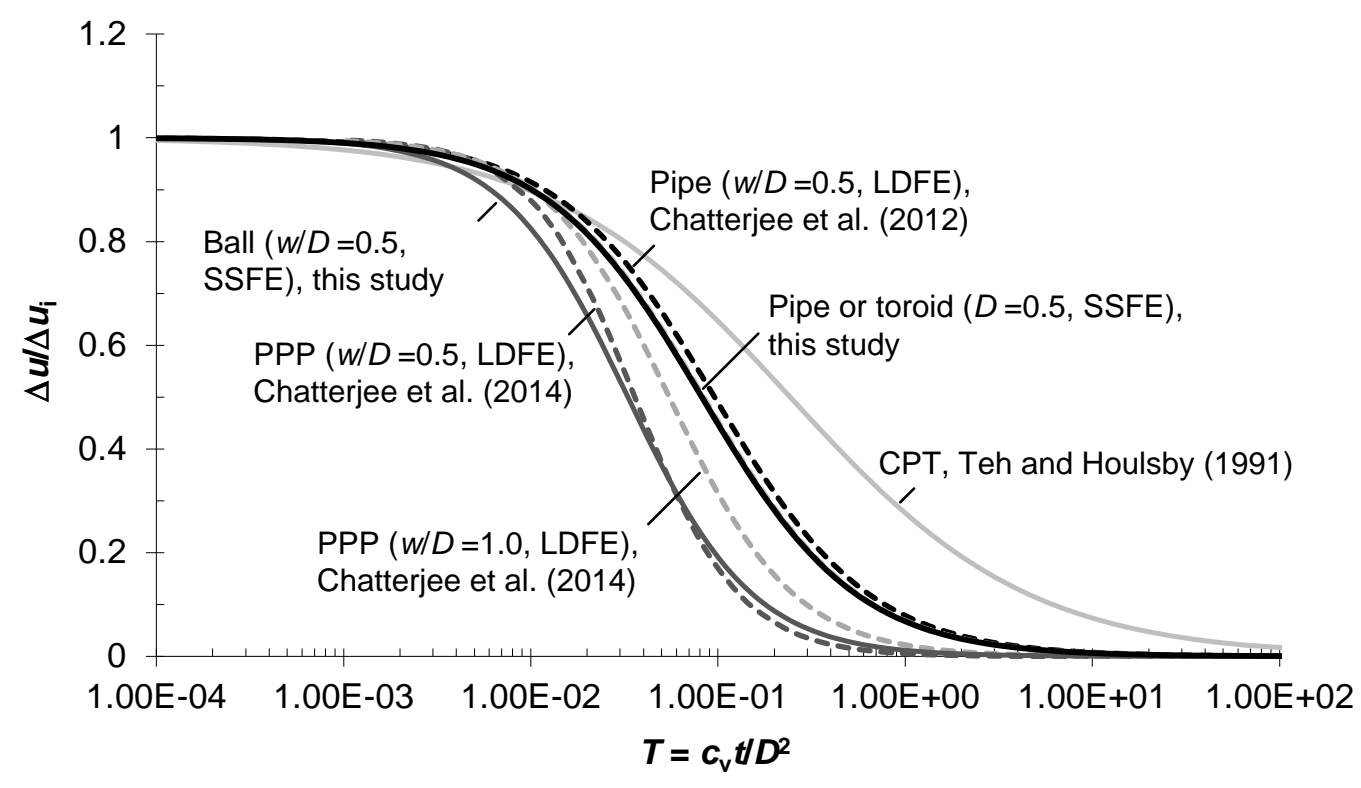

Figure 14 Excess pore pressure dissipation time histories at invert for smooth pipe and penetrometers in this study compared with CPT, pipe and PPP (Chatterjee et al., 2014) on homogeneous soilFigure 14 Excess pore pressure dissipation time histories at invert for smooth pipe and penetrometers in this study compared with CPT, pipe and PPP (Ghatterjee et al., 2014) on homogeneous soil 